\title{
Condições de crédito no Brasil rural ${ }^{1}$
}

\author{
Juliano Assunção* \\ Flávia Chein ${ }^{* *}$
}

Resumo: Este artigo documenta as condições de crédito das famílias que vivem em áreas rurais no Brasil. A análise é feita em duas etapas. Primeiro, utilizamos uma abordagem indireta onde o racionamento de crédito é associado à importância da riqueza para as decisões das famílias, através dos microdados dos Censos Demográficos de 1991 e 2000. Em seguida, utilizamos informações sobre crédito formal. Nossos resultados sugerem que (i) há fortes indícios de racionamento de crédito; (ii) há grande dispersão regional desse racionamento; e (iii) as condições de crédito das famílias rurais não guardam relação direta com o montante de crédito formal.

Palavras-chave: desenvolvimento rural, racionamento de crédito, educação.

Classificação JEL: H81, I20, O18.

${ }^{1} \mathrm{O}$ artigo se baseia em pesquisa financiada pela 'The United States Agency for International Development' (AID) e por um subcontrato da 'Broadening Access and Strengthening Input Market Systems’ (BASIS) / 'Collaborative Research Support Program’ (CRSP) / Universidade de Wisconsin-Madison com a Universidade da California em Riverside. As instituições acima não têm qualquer responsabilidade sobre as opiniões, resultados, conclusões e recomendações de política econômica do trabalho. Agradecemos os comentários e sugestões de Ângela Corrêa, Nelly de Figueiredo, Steven Helfand, Ajax Moreira, Eustáquio Reis e Gervásio Resende. Os erros remanescentes são de inteira responsabilidade dos autores.

*Doutor em Economia, Departamento de Economia - PUC-Rio. juliano@econ.puc-rio.br

**Doutora em Economia,CEDEPLAR, UFMG. fchein@cedeplar.ufmg.br 
Abstract: This paper presents the families' credit conditions in rural areas in Brazil. We perform the analysis in two steps. First, we follow an indirect approach, where the credit rationing is associated to the wealth importance in the families' decisions, using micro data from Demographic Census of 1991 and 2000. The second stage is based on information about formal credit. The results point out to: (i) strong evidences of credit rationing; (ii) an unequal regional distribution of this credit rationing; e (iii) no direct relationship between the families' credit conditions and the total availability of formal credit.

Key words: rural development, credit rationing, education.

JEL Classification: H81, I20, O18.

\section{Introdução}

A literatura econômica tem salientado que o mau funcionamento do mercado de crédito é um dos ingredientes necessários à ocorrência da armadilha de pobreza - o fato de que famílias são pobres por terem sido pobres em períodos anteriores ou terem se originado de outras famílias pobres. A falta de recursos necessários ao financiamento do investimento limita a capacidade das famílias de escapar da pobreza. Do ponto de vista agregado, essa incapacidade gera uma ineficiência, visto que os pobres não conseguem sair da sua condição de pobreza não porque são menos produtivos ou desprovidos das qualificações necessárias, mas, simplesmente, porque imperfeições de mercado impedem a realização plena de suas potencialidades (Galor e Zeira, 1993; Banerjee e Newman, 1993; Ghatak e Jiang, 2002).

Se por um lado o mercado de crédito tem um papel importante para a reprodução da condição de pobreza, por outro lado, diversas razões contribuem para a existência de imperfeições. Em geral, essas razões são determinadas por problemas de informação. Os provedores de crédito enfrentam uma série de dificuldades associadas ao contrato de crédito: não observam o tipo de seus clientes, o que eles fazem com os recursos emprestados ou se estão dispostos a repagar o empréstimo. Como resultado, essas imperfeições determi- 
nam o que é conhecido na literatura como racionamento de crédito (Ghosh, Mookherjee e Ray, 2000).

Especialmente no caso brasileiro, essas questões adquirem maior dimensão quando consideramos a população rural. Primeiro, porque um percentual maior da população pobre se concentra nas áreas rurais. Segundo, devido à maior distância dessa população ao mercado financeiro formal. Famílias que vivem em áreas rurais têm um custo de acesso maior ao mercado financeiro, o que limita suas possibilidades de crédito e suavização de risco. E ainda, devido a essa distância, os problemas de assimetria de informação mencionados acima são exacerbados.

Nesse contexto, grande parte da literatura sobre crédito rural no Brasil, na qual se incluem os trabalhos de Brandão e Magalhães (1982), Rezende (1985), Rezende e Buainain (1994), Gasques et al. (2004), Mattei (2001), Dias et al. (2004), Neder et al. (2005), tem sido direcionada para a questão da reforma agrária e de programas governamentais de financiamento de agricultores familiares. Não há estudos sobre o racionamento de crédito das famílias que vivem em áreas rurais.

Este artigo documenta a evolução recente do racionamento de crédito para a população rural brasileira. A análise é feita em duas etapas.

Inicialmente, o racionamento de crédito é associado a uma correlação entre riqueza e escolhas, como em Evans e Jovanovic (1989). Se a restrição de crédito é ativa, a riqueza individual se torna um dos determinantes das decisões das famílias. Caso contrário, essas decisões são completamente determinadas pela avaliação de custos e benefícios. Quanto mais restritivo for o racionamento, maior é o efeito da riqueza das famílias sobre suas decisões. Essa estratégia tem a vantagem de contornar problemas associados à disponibilidade de dados. O mercado de crédito é visto, nesse caso, como o conjunto de práticas, formais ou informais, que possibilitam o financiamento de alguma atividade.

As bases de dados utilizadas consistem nos microdados dos Censos Demográficos de 1991 e 2000. A análise empírica tem dois aspectos que merecem destaque. Primeiro, não dispomos informações explícitas sobre o patrimônio das famílias. Portanto, a partir de uma análise de componentes principais envolvendo informações sobre a posse de bens duráveis, condições de moradia e acesso à infra-estrutura pública, é criada uma medida de riqueza. Em seguida, essa variável é utilizada em 
regressões da riqueza sobre (i) educação infantil e (ii) a probabilidade do chefe da família ser um empregador, controlando para um amplo conjunto de variáveis observadas. O segundo aspecto que merece destaque é o uso de uma amostra de famílias cujo chefe tem idade entre 20 e 29 anos, visando atenuar o efeito das escolhas das famílias sobre a acumulação da riqueza.

Os principais resultados são os seguintes: Considerando a educação como variável dependente, a análise agregada aponta para a existência de racionamento de crédito no Brasil rural em 2000. Famílias com índice de riqueza mais baixo apresentam uma escolaridade menor de seus filhos em relação à média da microrregião. Quando comparamos 1991 com 2000, vimos que houve, em termos agregados, uma piora no racionamento. Ao desagregar a análise para as cinco macrorregiões brasileiras, notamos importantes diferenças. $\mathrm{O}$ racionamento de crédito para a educação infantil é mais intenso no Nordeste, Centro-Oeste e Sul. No caso do Norte e Nordeste, o efeito está concentrado no período $1991 / 2000$, enquanto nas demais regiões, o período não representou mudanças na restrição de crédito. Considerando a probabilidade de o chefe ser um empregador, a restrição de crédito é mais importante nas áreas Sudeste e Sul do país.

Ao desagregar a análise em microrregiões, mostramos que o racionamento de crédito, considerando a educação infantil como variável de escolha, é maior nas áreas com alto percentual de crianças que sabem ler e escrever e alto percentual de crianças na escola em 2000. Ao considerar a evolução do período 1991/2000, verificou-se uma piora da restrição de crédito nas áreas com renda familiar per capita baixa, pouca escolaridade do chefe da família e com baixo percentual de crianças que sabem ler e escrever. A restrição de crédito, quando considerada a decisão do chefe se ocupar como empregador, é mais intensa nas áreas com maior renda familiar per capita em 2000.

A segunda etapa da análise utiliza duas fontes de informações sobre crédito formal: i) dados do Plano Contábil das Instituições do Sistema Financeiro Nacional (COSIF), disponibilizados pelo Banco Central do Brasil; e ii) os resultados consolidados do PRONAF (Programa Nacional de Fortalecimento da Agricultura Familiar). No primeiro tipo de informação, consideramos o montante médio de crédito concedido durante 
os anos de 1991 e 2000 - anos para os quais temos informações censitárias. Dessa maneira, podemos não apenas caracterizar a distribuição regional do montante de recursos emprestados e sua evolução na década de 1990, como podemos comparar a concessão de crédito formal com os indicadores de racionamento de crédito gerados na primeira parte do trabalho. Para o PRONAF, utilizamos dados referentes ao período de 2000 a 2004, de modo a obter uma noção da evolução recente de um mecanismo de crédito direcionado para uma parcela específica de produtores rurais, classificados como agricultores familiares.

Em linhas gerais, o montante total das operações de crédito sofreu um leve aumento entre 1991 e 2000. Há uma concentração de recursos nas áreas mais desenvolvidas do país, apesar de que a variação ao longo da década de 1990 privilegiou áreas mais pobres. O montante de crédito bancário em 2000, por sua vez, esteve positivamente correlacionado com a renda familiar per capita, indicadores de educação, urbanização e produtividade agrícola, a evolução entre 1991 e 2000 é negativamente correlacionada com todos esses fatores.

Ao considerar as modalidades de crédito específicas à agropecuária, notamos diferenças importantes. A evolução do volume de crédito para investimento e custeio da agricultura seguiu o padrão do crédito total, concentrando-se em áreas com renda familiar per capita mais baixa, menos educação e menor produtividade. Ao contrário, a variação do crédito para o investimento e custeio da pecuária se concentrou em áreas com maior renda familiar per capita, mais educação e mais urbanizadas.

De outro lado, quando analisamos os créditos concedidos pelo PRONAF, verificamos um aumento acentuado tanto no montante de financiamentos como no total de contratos entre 2002 e 2004. Entretanto, parece haver uma forte correlação do volume de recursos concedidos pelo PRONAF, na modalidade custeio, e indicadores de maior desenvolvimento, como anos de estudo, e média da renda familiar per capita.

Finalmente, a comparação dos indicadores de racionamento de crédito com a evolução do crédito bancário ilustra como a necessidade de crédito de famílias rurais não está necessariamente vinculada ao crédito formal. As áreas onde houve maior expansão do crédito bancário são justamente as áreas onde o racionamento de crédito, considerando a educação infantil como variável dependente, é mais 
intenso em 2000 e sofreu um maior aperto entre 1991 e 2000. Por outro lado, considerando a decisão de o chefe da família ser empresário, o racionamento é maior onde há menos recursos para o investimento, custeio e comercialização da agricultura.

Esses resultados contribuem para um melhor entendimento das condições de crédito das famílias que vivem em áreas rurais no Brasil e sua relação com o crédito bancário formal. Pouco se sabe sobre o assunto no Brasil. Os poucos trabalhos que existem se concentram no acesso a crédito em áreas urbanas. Além de mostrar fortes indícios de racionamento de crédito em várias áreas, nossos resultados mostram que há uma fraca relação desse racionamento com modalidades de crédito bancário.

O restante do artigo está organizado da seguinte forma. A próxima seção estabelece os fundamentos para a análise do racionamento de crédito com base na relação entre riqueza e decisões. Em seguida, a seção 2 apresenta a base de dados utilizada e a construção do índice de riqueza. A seção 3 descreve os resultados principais da abordagem utilizando as escolhas de educação infantil e a probabilidade de o chefe se ocupar como empregador, considerando três níveis de agregação - Brasil, macrorregiões e microrregiões. A seção 4 considera as estatísticas provenientes do sistema COSIF sobre o crédito bancário formal e do PRONAF, suas relações com indicadores sócio-econômicos e com as medidas de racionamento de crédito estimadas na seção 3. A conclusão do artigo é apresentada em seguida.

\section{Racionamento de crédito e decisões}

A aferição empírica do racionamento de crédito tem, como um de seus principais obstáculos, a ausência de dados. Poucas são as oportunidades de mensuração das reais condições de crédito das famílias. Em larga medida, essas dificuldades estão associadas à grande variedade de modalidades de crédito disponíveis no cotidiano dessas pessoas. Compras a fiado, cadernetas de compra, cheques pré-datados e prazos com fornecedores são apenas alguns exemplos de operações de crédito que estão fora do alcance das pesquisas disponíveis no Brasil. Além dos problemas associados diretamente à contabilização das operações de crédito, outras dificuldades surgem quando os indivíduos utilizam 
uma modalidade de crédito como forma de liberação de recursos para o financiamento de outras atividades. Por exemplo, o crédito para a compra de mercearia pode ser utilizado como uma forma de financiar gastos com a compra de material escolar.

Dessa forma, a análise empírica se depara com um problema de ausência de dados que torna complicada a identificação do racionamento de crédito. Com o objetivo de contornar essa dificuldade, utilizamos uma estratégia indireta que se baseia na análise das decisões familiares quando restritas pelo crédito.

Considere um indivíduo representativo de uma família, descrito pelo par $(\theta, a)$, onde $\theta$ corresponde às características específicas do indivíduo e $a$ é a riqueza inicial. Esse indivíduo se depara com uma escolha $e \in \mathfrak{R}$, que tem custos representados por $C(e, \theta)$, onde $C_{e}>0, C_{e e}>0$ e $C_{\theta}>0$, e uma utilidade representada pela função $u(e, \theta)$, onde $u_{e}>0$ e $u_{e e}<0$.

Na ausência de um mercado de crédito, a escolha precisa ser financiada pela riqueza inicial do indivíduo. No caso em que o mercado de crédito existe e está sujeito aos problemas de informação resumidos em Ghosh, Mookherjee e Ray (2000), o montante de recursos disponíveis para o financiamento de $e$ é uma função crescente $M(a)$ da riqueza inicial da família $a$. Dessa forma, a decisão da família $(\theta, a)$ é descrita pelo seguinte problema:

$$
U(\theta, a) \equiv \max _{e} u(e, \theta) \text { s.a. } C(e, \theta) \leq M(a),
$$

cujas condições de primeira ordem são dadas por:

$$
\begin{aligned}
& u_{e}\left(e^{*}, \theta\right)=\lambda^{*} C_{e}\left(e^{*}, \theta\right), \\
& \lambda^{*}\left[C\left(e^{*}, \theta\right)-M(a)\right] \leq 0 \text { e } \lambda^{*} \geq 0,
\end{aligned}
$$

onde $\lambda^{*}$ é o multiplicador de Lagrange associado à restrição de crédito. O multiplicador $\lambda^{*}$ é estritamente positivo se, e somente se, a restrição de crédito é ativa.

Manipulando (C1) e (C2), temos duas possibilidades distintas para a escolha ótima de $e$ : 


$$
e^{*}(\theta, a)=\left\{\begin{array}{cc}
f(\theta), & \text { se } \lambda^{*}=0, \\
g(\theta, a), & \text { se } \lambda^{*}>0 .
\end{array}\right. \text { (E) }
$$

A função $f$ é a inversa de $u$ com respeito à primeira variável, avaliada em 0 , isto é, $f(\theta) \equiv u^{-1}(0, \theta)$. Para cada $\theta$, a função $u$ é estritamente crescente em $e$ e, portanto, $f$ é bem definida. A função $g$ é definida de forma análoga por $g(\theta, a) \equiv C^{-1}(M(a), \theta)$.

Note que a riqueza importa para a escolha ótima $e^{*}(\theta, a)$ apenas se há restrição de crédito. Nesse caso, a família escolhe o maior $e$ que pode financiar com o montante de recursos que consegue obter com o seu estoque de ativos $a$. Diferenciando (E) com respeito a $a$ e substituindo (C1), temos que:

$$
\frac{d}{d a} e^{*}(\theta, a)=\frac{\lambda^{*}}{u_{e}\left(e^{*}(\theta, a), \theta\right)} M^{\prime}(a)>0 .
$$

A equação (D) mostra que, quanto maior o valor sombra da restrição de crédito, $\lambda^{*}$, maior é o efeito da riqueza sobre a escolha ótima da família. Caso a restrição não seja ativa, $\lambda^{*}=0$, a riqueza não afeta a decisão ótima.

A análise empírica a seguir tem como base uma aproximação linear para a equação (E), considerando as escolhas de educação das crianças e decisão do chefe se ocupar como empregador. Na abordagem empírica, parte das características das famílias é observada, $\beta^{\prime} X$, mas ainda há uma outra parcela remanescente $\varepsilon$ que não é observada pelo econometrista. Logo, iremos considerar a seguinte especificação linear para a família $i$ :

$$
e^{*}\left(\theta_{i}, a_{i}\right)=e^{*}\left(\beta^{\prime} X_{i}+\varepsilon_{i}, a_{i}\right)=\alpha a_{i}+\beta^{\prime} X_{i}+\varepsilon_{i} .
$$

Sob as hipóteses usuais, (EQ) pode ser estimada por mínimos quadrados ordinários.

\section{Descrição da base de dados}

A base de dados utilizada foi construída a partir das informações para pessoas e domicílios dos Censos Demográficos do Brasil, realizados pelo Instituto Brasileiro de Geografia e Estatística (IBGE), a cada 
dez anos. A grande vantagem dos Censos Demográficos sobre outras pesquisas domiciliares é a sua abrangência nacional e representatividade para níveis regionais menores tais como microrregiões e municípios, o que permite a identificação de heterogeneidades espaciais.

A amostra aqui considerada engloba os residentes em domicílios rurais nos Censos Demográficos de 2000 e 1991. Além disso, restringiuse a amostra para os domicílios onde residia uma única família, cujo chefe tinha entre 20 e 29 anos. Tal restrição visa mitigar o problema de endogeneidade entre riqueza e escolha ocupacional. Por um lado, a riqueza determina a escolha ocupacional, por outro, a ocupação é um determinante da renda, influenciando, portando, a riqueza. Sob a hipótese de que a riqueza dos jovens é menos determinada pelas suas escolhas passadas, restringir a idade dos chefes de família atua no sentido de eliminar esse segundo efeito.

Para essa amostra, foram consideradas tanto variáveis relativas às características individuais como variáveis que denotam as condições de moradia, como existência de rede geral de abastecimento, coleta de lixo, iluminação elétrica, e acesso a bens de consumo durável, como geladeira, televisão, automóvel. Tais variáveis representam uma proxy da riqueza dos indivíduos, construída a partir de uma análise de componentes principais, conforme apresentado na Tabela 1. A nova variável, denominada riqueza resultante, é uma combinação linear, obtida a partir da matriz de correlação, de 16 variáveis associadas a características do domicílio, capaz de explicar, em 1991 e em 2000, respectivamente $30.4 \%$ e $31.7 \%$ da variância entre os dados originais. Note que as únicas alterações de peso relativo ocorreram para o acesso à rede geral de esgoto e o número de empregados domésticos.

Logo, como as características dos domicílios são investigadas apenas para os domicílios particulares permanentes, não foram incluídos, na amostra, os residentes em domicílios coletivos ou improvisados. Além disso, como era preciso associar a riqueza do domicílio à família, foram excluídas da análise os domicílios com mais de uma família residente.

A amostra final considerada, para o ano de 1991 e 2000 é composta por, respectivamente, 168.964 e 154.787 famílias. Para essas famílias foram analisadas variáveis dos chefes de família, do cônjuge, dos filhos e da sua própria composição. 
Tabela 1 - Análise de Componente Principal - Resultado do $1^{\circ}$. Componente

\begin{tabular}{l|r|r}
\hline \multicolumn{1}{c|}{ Coeficientes } & \multicolumn{1}{c}{$\mathbf{1 9 9 1}$} & \multicolumn{1}{c}{$\mathbf{2 0 0 0}$} \\
\hline Possui domicílio Próprio & -0.085842 & -0.084317 \\
Total de cômodos & 0.211344 & 0.181095 \\
Tem banheiro no domicílio & 0.360718 & 0.356715 \\
Existência de Sanitário & 0.328430 & 0.347063 \\
Existência de rede geral de abastecimento de água & 0.177390 & 0.158682 \\
Existência de água canalizada & 0.354442 & 0.340462 \\
Existência de rede geral de esgoto & 0.151304 & 0.347063 \\
Existência de coleta de lixo & 0.199038 & 0.208718 \\
Existência de iluminação elétrica & 0.334589 & 0.301024 \\
Possui linha telefônica & 0.113304 & 0.132718 \\
Possui geladeira ou freezer & 0.355556 & 0.338485 \\
Possui rádio & 0.186135 & 0.160353 \\
Possui TV & 0.349926 & 0.304270 \\
Possui máquina de lavar & 0.213967 & 0.176092 \\
Número de Empregados Domésticos & 0.055612 & 0.012398 \\
Possui automóvel & 0.182204 & 0.187162 \\
\hline Variância Explicada & $30.42 \%$ & $31.87 \%$ \\
\hline
\end{tabular}

Fonte: Elaboração Própria.

Basicamente, a análise se concentra em dois tipos de decisão: a educação dos filhos e enteados com idade entre sete e 14 anos e a probabilidade do chefe de família ser empresário. Na amostra selecionada existem 35.031 crianças ( $57.50 \%$ com idade até oito anos), em 1991, e 36.628, em 2000 (55.45\% tinham até oito anos de idade). Para essas crianças a média de anos de estudo cresceu de 0.47 anos, em 1991, para 0.98, em 2000. A análise da média de anos de estudo por microrregiões denota uma desigualdade acentuada, com média inferior a um ano de estudo, em muitas microrregiões do Norte de Nordeste e superior a dois em algumas microrregiões do Sudeste e Sul, como representado no Mapa A da Figura 1.

Como empresário foram considerados os chefes de família cuja posição na ocupação era a de empregador. Entre os Censos Demográficos de 1991 e 2000, há uma queda acentuada na proporção de empregadores sobre o total de ocupados. Considerando os residentes tanto em áreas rurais e urbanas, a proporção de empregadores, em 1991, era de 
$5.57 \%$, contra apenas $4.09 \%$ em 2000. Entre os domicílios chefiados por jovens entre 20 e 29 anos, houve queda de $3.13 \%$ para $1.72 \%$. Analisando apenas os residentes em domicílios rurais, a queda foi de 3.7\% para $2.86 \%$, sendo que entre os chefes entre 20 e 29 anos, a proporção caiu de $2 \%$ para $0.72 \%$ no período.

Figura 1 - Análise Regional da Média de Educação e Percentual de Empresários
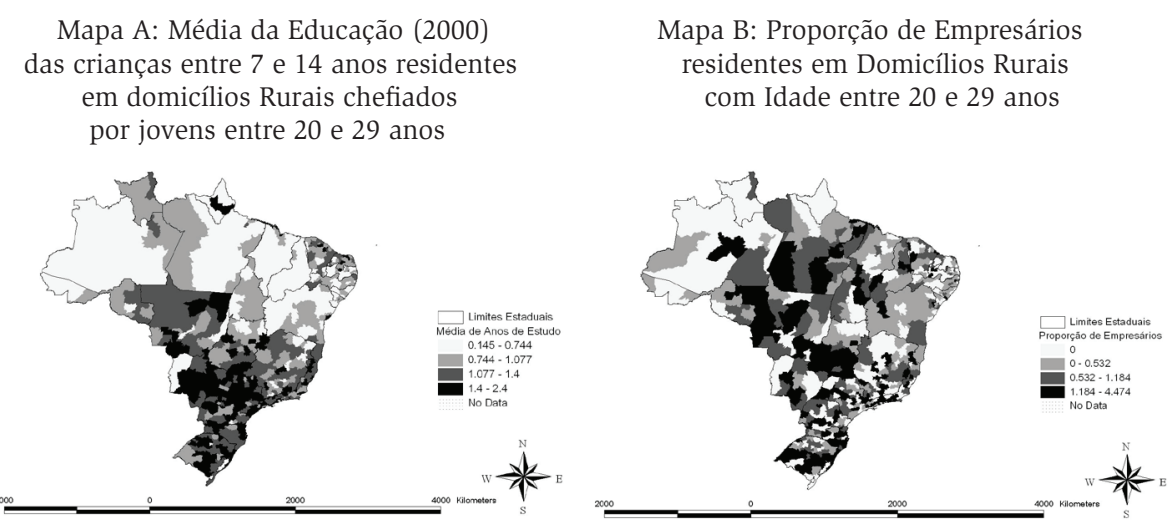

Fonte: Elaboração própria a partir de dados do Censo Demográfico 2000 (IBGE).

Muito mais do que um reflexo de mudanças estruturais severas, tal resultado parece ser decorrente de alterações metodológicas entre o questionário da pesquisa aplicada em 1991 e em 2000. No Censo de 1991, as questões sobre mercado de trabalho perguntavam sobre a ocupação e atividade no período de referência, ou seja, entre agosto de 1990 e agosto de 1991. Com o Censo 2000, tais questões passaram a ter como horizonte a semana de referência ao invés de ano. Verifica-se, na amostra selecionada, que a redução na proporção de empregadores de $2 \%$ para $0.72 \%$ é acompanhada por um aumento na proporção de trabalhadores não remunerados (de 0.42 para $9.42 \%$ ). Além disso, a queda na proporção de empregadores é mais forte na agricultura e pecuária, em torno de $27 \%$. Talvez isso seja uma evidência de que os empregadores do setor agrícola contratam trabalhadores de acordo com a sazonalidade das colheitas e plantio.

Há, portanto, fortes evidências de que as alterações metodológicas tornam difícil uma análise comparativa entre as decisões de se tornar 
empresário em 1991 e em 2000. Daí, a decisão por considerar apenas o Censo de 2000 no que se refere a essa decisão do chefe de família. Pelo Mapa B da Figura 1, constata-se que nas regiões menos desenvolvidas, como Nordeste e extremo Norte do país, há uma menor proporção de empresários, sendo nula em regiões mais pobres, como o norte de Minas e semi-árido nordestino.

\section{Resultados empíricos}

Essa seção explora a relação entre a riqueza da família e suas decisões de investimento, em especial, como foi explicitada anteriormente, a relação entre a riqueza e os anos de estudo das crianças e a probabilidade do chefe da família ser empregador, ou melhor, ter o próprio negócio.

Para as crianças, é investigada a relação entre a riqueza e o diferencial de educação, definido como a diferença entre os anos de estudo do indivíduo e a média de anos de estudo de crianças com a mesma idade, residentes na mesma microrregião, num dado período. Essa análise é realizada em duas etapas. Primeiro, é avaliada a situação do racionamento de crédito em 2000. Em seguida, analisa-se a evolução da restrição de crédito entre 1991 e 2000, de modo a documentar mudanças estruturais recentes. Em ambas as análises são considerados três níveis regionais: Brasil, macrorregiões e microrregiões.

Já para a probabilidade do chefe ser empresário é feita apenas a primeira etapa da análise dada as impossibilidades de se realizar uma análise longitudinal, envolvendo os anos de 1991 e 2000, decorrentes das já explicitadas alterações metodológicas da pesquisa.

Antes de proceder à análise sistemática dessas relações, exploramos de forma preliminar, através de estatísticas descritivas básicas, as informações sobre educação infantil e proporção de empregadores em nossa amostra.

\subsection{Análise preliminar}

A equação (D) sugere que a relação entre riqueza e a implementação de decisões favoráveis se torna tão mais forte quanto maiores forem as restrições do mercado de crédito. $\mathrm{O}$ aumento da riqueza significa um 
afrouxamento da restrição de crédito, o que torna possíveis decisões antes inviáveis, seja em termos de escolha ocupacional seja em termos de investimento na educação dos filhos. A hipótese considerada é a de que essas decisões são dependentes da dotação inicial dos agentes. Dessa forma, a probabilidade de um chefe de família pertencente aos décimos superiores da distribuição de riqueza optar por abrir o próprio negócio em detrimento de um trabalho assalariado tende a ser maior do que aqueles dos primeiros décimos da distribuição. Situação similar ocorre com a decisão de colocar ou não os filhos na escola.

Uma análise preliminar dessa relação é obtida pelos dados apresentados na Figura 2. Pelo Gráfico A, é possível perceber que a média de anos de estudo é bastante superior para os décimos superiores de riqueza. Além disso, percebe-se que as diferenças, em 1991, são muito pequenas entre os três décimos mais pobres. Em 2000, há uma elevação, em todos os décimos, da média de anos de estudo, e os $10 \%$ mais pobres aparecem, como esperado, com a menor média de escolaridade. É necessário destacar que uma elevação de renda do primeiro para o segundo décimo da distribuição gera um grande efeito positivo nos anos de estudo, mas os aumentos de riqueza subseqüentes, isto é, do segundo para terceiro e do terceiro para o quarto décimo, têm um reflexo pequeno sobre a média de anos de estudo das crianças. Os maiores efeitos do aumento de riqueza ocorrem entre as mudanças de classes para os $50 \%$ mais ricos, exceção feita para a passagem dos $60 \%$ mais ricos para os $70 \%$.

Quanto à proporção de chefes empresários, apresentadas no Gráfico $B$, além dos evidentes reflexos das mudanças metodológicas na pesquisa, percebe-se, na série para o ano 2000, que os efeitos do aumento de riqueza sobre a decisão de se tornar empresário aparecem de modo acentuado apenas nas camadas mais ricas da população, ou seja, aumentos reduzidos na riqueza para os mais pobres são pouco eficazes no sentido de alterar suas escolhas ocupacionais, de modo a incentivar a troca do trabalho assalariado pelo próprio negócio.

Tais evidências apontam na direção de uma investigação empírica mais formal com o intuito de identificar mais claramente este possível vínculo entre estoque de ativos e decisões intra-familiares, o que será apresentado na seção seguinte. 
Figura 2 - Relação entre Riqueza e Decisões Intra-Familiares
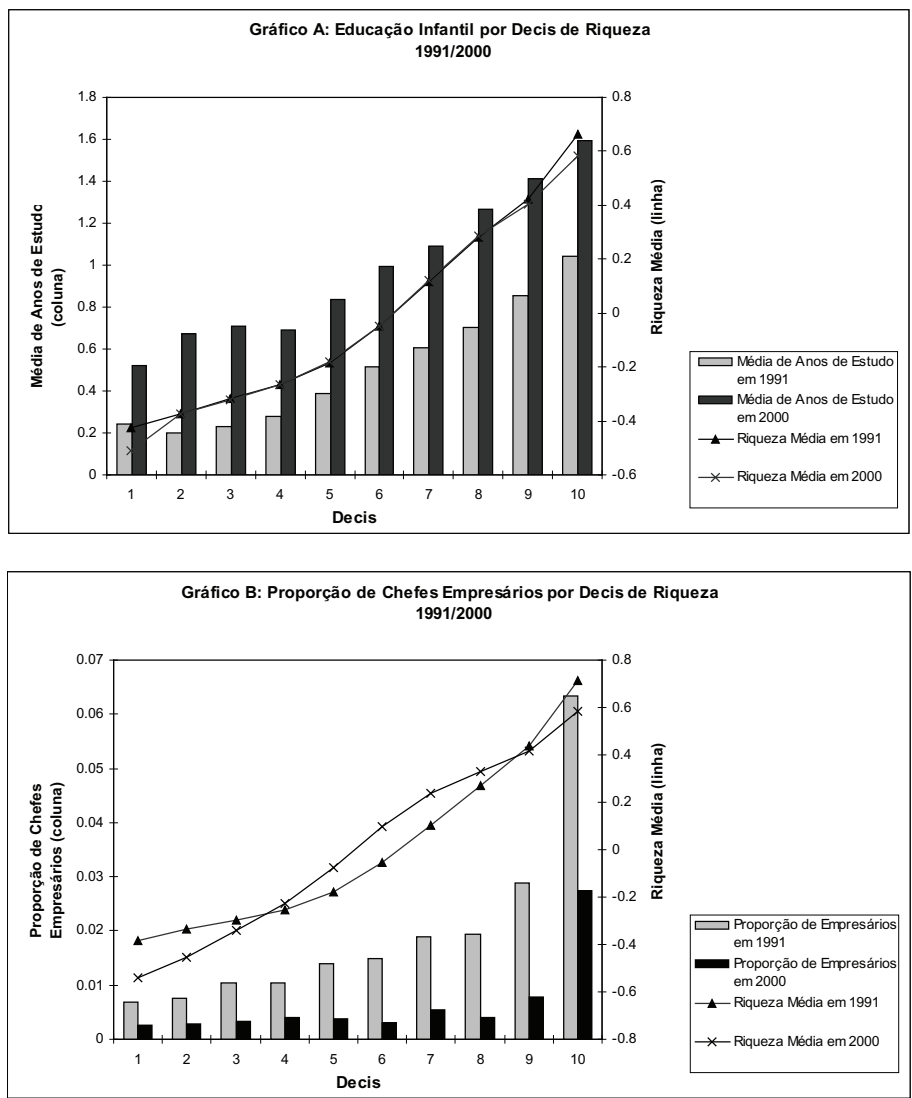

Fonte: Elaboração própria a partir de dados dos Censos Demográficos 1991/2000 (IBGE).

\subsection{Restrição de crédito e educação infantil}

As Tabelas 2 e 3 apresentam, respectivamente, os resultados das regressões das estimações de Mínimos Quadrados Ordinários para o efeito do racionamento de crédito em 2000 e da evolução da restrição entre 1991 e 2000 sobre o diferencial de educação individual. Nessas regressões, são incluídas, além da variável riqueza, os seguintes controles: dummies de região (na estimação para Brasil); características individuais, do chefe da família e do seu cônjuge, como também variáveis da família. 
As dummies de região captam diferenças regionais no retorno à educação, nas políticas educacionais existentes, no custo de vida, bem como na oferta e demanda de vagas escolares, entre outras.

A inclusão de variáveis relativas às características individuais como sexo, idade, ordem entre os irmãos, ser filho único, objetiva controlar para questões como o viés de alocação de recursos entre os filhos. Para o ano 2000, são incluídas, nesse grupo de controles, variáveis relativas ao trabalho infantil, considerando-se que, grande parte das vezes, a escolha dos pais é entre investir na educação dos filhos ou inseri-los precocemente no mercado de trabalho. Na análise da evolução da restrição de crédito esses últimos controles não foram incluídos pelo fato de ser difícil avaliar a questão do trabalho infantil em decorrência da semana de referência do Censo 2000 (23 a 29 de julho) incluir um período de férias escolares.

Os demais controles objetivam excluir, do coeficiente da variável riqueza, efeitos associados à escolaridade, trabalho dos pais e tamanho da família. Espera-se, por exemplo, que pais mais educados estejam mais dispostos a investir na educação dos filhos e, ao mesmo tempo, sejam mais preparados para auxiliar as crianças nos trabalhos escolares (Behrman, Foster, Rosenzweig e Vashishtha, 1997). Entretanto, como o foco central do artigo é o efeito da restrição de crédito em si sobre a educação, os resultados coeficientes das variáveis de controle não serão aqui explorados.

Os resultados do modelo de Mínimos Quadrados Ordinários para estimação da educação diferencial, em 2000, sugerem um efeito positivo e fortemente significativo da riqueza sobre a diferença entre os anos de escolaridade da criança e a média de escolaridade das crianças com a mesma idade, na mesma microrregião. Pela Tabela 2, verifica-se que, para o Brasil, o aumento de uma unidade da riqueza (um desviopadrão) elevaria a educação diferencial em 0.214. Esse efeito tende a ser ainda maior no Centro-Oeste (0.252) e menor no Sudeste (0.140), indicando que, provavelmente, a relação entre restrição de crédito e educação tende a ser mais frouxa nessa região. Isso não significa que, necessariamente, as imperfeições do mercado de crédito sejam menores no Sudeste, mas talvez o acesso à educação seja menos custoso comparativamente às demais regiões. 
Tabela 2 - Educação Relativa (OLS) por Região (2000)

\begin{tabular}{|c|c|c|c|c|c|c|}
\hline & Brasil & Norte & Nordeste & $\begin{array}{c}\text { Centro- } \\
\text { Oeste }\end{array}$ & Sudeste & Sul \\
\hline Riqueza & $0.214^{* * *}$ & $0.158^{* * *}$ & $0.223 * * *$ & $0.252 * * *$ & $0.140 * * *$ & $0.222 * * *$ \\
\hline Sexo & $-0.124 * * *$ & $-0.115 * * *$ & $-0.169 * * *$ & $-0.124 * * *$ & $-0.100 * * *$ & -0.019 \\
\hline Idade & $-0.015^{* * *}$ & $-0.033^{* * *}$ & $-0.025 * * *$ & $0.036^{* *}$ & $-0.024 * * *$ & $0.026 * *$ \\
\hline Ordem entre os irmãos & $0.051 * * *$ & $0.065 * * *$ & $0.089 * * *$ & -0.081 & $0.071 * * *$ & -0.036 \\
\hline Filho único & $-0.083 * * *$ & -0.046 & $-0.084 * * *$ & 0.024 & $-0.119 * * *$ & $-0.102 * *$ \\
\hline Está ocupado & $-0.213^{* * *}$ & $-0.225^{*}$ & $-0.240 * *$ & 0.18 & $0.422 * *$ & $-0.653 * * *$ \\
\hline $\begin{array}{l}\text { Total de horas } \\
\text { trabalhadas }\end{array}$ & $0.007^{* * *}$ & $0.010 * *$ & $0.006 * *$ & -0.012 & -0.001 & $0.012 * *$ \\
\hline \multicolumn{7}{|l|}{$\begin{array}{l}\text { Variáveis do Chefe de } \\
\text { Família }\end{array}$} \\
\hline Está ocupado & 0.001 & -0.044 & $0.058^{*}$ & -0.085 & -0.056 & -0.001 \\
\hline $\begin{array}{l}\text { Total de } \\
\text { trabalhac }\end{array}$ & 0 & 0.001 & $-0.002 * * *$ & 0 & 0.001 & 0 \\
\hline Renda & $0.000 * *$ & $0.000 * *$ & $0.000^{*}$ & 0 & 0 & $0.000 * *$ \\
\hline 1-4 anos de estudo & $0.028^{*}$ & 0.011 & $0.048 * * *$ & 0.06 & -0.045 & -0.075 \\
\hline 5-8 anos de estudo & $0.057 * * *$ & 0.055 & $0.126^{* * *}$ & 0.093 & -0.048 & -0.068 \\
\hline 9-11 anos de estudo & $0.115^{* * *}$ & $0.117^{*}$ & $0.154^{* * *}$ & 0.153 & 0.01 & 0.063 \\
\hline $\begin{array}{l}12 \text { ou mais anos de } \\
\text { estudo }\end{array}$ & 0.029 & 0.057 & -0.068 & -0.198 & 0.08 & 0 \\
\hline Idade & -0.046 & 0.099 & -0.025 & -0.244 & $-0.142^{*}$ & -0.083 \\
\hline Idade $^{2}$ & 0.001 & -0.002 & 0.001 & 0.005 & $0.003^{*}$ & 0.002 \\
\hline Sexo & 0.019 & 0.005 & 0.044 & 0.127 & 0.021 & 0.043 \\
\hline Não sabe ler e escrever & $-0.072 * * *$ & -0.053 & $-0.060 * * *$ & $-0.166^{* *}$ & $-0.076^{*}$ & $-0.122 * *$ \\
\hline É empresário & 0.044 & 0.002 & 0.039 & 0.068 & -0.113 & 0.135 \\
\hline \multicolumn{7}{|l|}{ Variáveis do Cônjuge } \\
\hline Está ocupado & $0.031^{*}$ & 0.044 & 0.025 & -0.031 & 0.053 & -0.058 \\
\hline $\begin{array}{l}\text { Total de horas } \\
\text { trabalhadas }\end{array}$ & 0 & 0.001 & 0 & 0.001 & -0.001 & 0.002 \\
\hline Renda & 0 & 0 & $0.000 * * *$ & 0 & 0 & 0 \\
\hline 1-4 anos de estudo & $0.053 * * *$ & 0.028 & $0.064 * * *$ & -0.004 & $0.140 * * *$ & -0.05 \\
\hline 5-8 anos de estudo & $0.128 * * *$ & $0.176^{* * *}$ & $0.131 * * *$ & 0.127 & $0.184^{* * *}$ & -0.036 \\
\hline 9-11 anos de estudo & $0.272 * * *$ & $0.441 * * *$ & $0.222 * * *$ & 0.191 & $0.278 * * *$ & 0.133 \\
\hline $\begin{array}{l}12 \text { ou mais anos de } \\
\text { estudo }\end{array}$ & 0.124 & $-0.540^{*}$ & 0.141 & -0.193 & 0.093 & $0.304^{*}$ \\
\hline Idade & $0.018^{* * *}$ & $0.015^{* * *}$ & $0.014^{* * *}$ & $0.027^{* * *}$ & $0.025 * * *$ & $0.013^{*}$ \\
\hline Idade $^{2}$ & $-0.000 * * *$ & 0 & $-0.000 * *$ & $-0.000 * *$ & $-0.000 * * *$ & 0 \\
\hline Não sabe ler e escrever & $-0.100 * * *$ & -0.063 & $-0.092 * * *$ & -0.144 & $-0.077^{*}$ & $-0.244^{* * *}$ \\
\hline É empresário & -0.192 & -0.176 & $0.784^{*}$ & -2.029 & -0.624 & $-0.812^{*}$ \\
\hline
\end{tabular}




\begin{tabular}{lcrrrrr}
\hline Variáveis da Família & & & & & & \\
\hline Número de filhos & $-0.066^{* * *}$ & -0.024 & $-0.119^{* * *}$ & -0.009 & -0.019 & $-0.081^{*}$ \\
Número de filhas & $-0.065^{* * *}$ & -0.006 & $-0.125^{* * *}$ & -0.027 & -0.038 & -0.049 \\
$\begin{array}{l}\text { Pelo menos um dos } \\
\text { filhos trabalha }\end{array}$ & $-0.056^{* *}$ & -0.06 & $-0.065^{*}$ & -0.051 & $-0.100^{*}$ & 0.09 \\
$\begin{array}{l}\text { Média de idade dos } \\
\text { filhos }\end{array}$ & $0.018^{* * *}$ & $0.036^{* * *}$ & $0.036^{* * *}$ & -0.029 & $0.011^{*}$ & $-0.014^{*}$ \\
$\begin{array}{l}\text { Número de pessoas na } \\
\text { Família }\end{array}$ & -0.003 & -0.038 & 0.03 & 0.029 & -0.025 & 0.005 \\
\hline Dummies de Região & Sim & - & - & - & - & - \\
\hline Constante & 0.001 & -1.523 & -0.079 & 2.221 & 1.172 & 0.767 \\
\hline Observações & 33429 & 5830 & 14183 & 2368 & 7054 & 3994 \\
\hline
\end{tabular}

* significante a $10 \%$; ${ }^{*}$ significante a $5 \%$; ${ }^{* *}$ significante a $1 \%$.

Embora não seja esse o foco do trabalho, é importante destacar que a educação dos pais nas Regiões Centro-Oeste e Sul parece não influenciar, pelo menos diretamente, a escolaridade dos filhos. No Centro-Oeste, o único efeito encontrado é o efeito negativo do chefe de família não ser alfabetizado. Já para a Região Sul, além da alfabetização do pai, importa também a alfabetização da mãe, tendo sido encontrado também um efeito, ainda que pouco significativo, da escolaridade do cônjuge com mais de 12 anos de estudo.

De outro lado, os coeficientes encontrados para variável referente ao trabalho infantil também sugerem alguns efeitos interessantes. Na região Sul, parece que as ocupações do trabalho infantil são mais dedicadas, ou seja, exigem mais das crianças, representando uma dificuldade maior para conciliar as atividades de estudo e trabalho. Opostamente, na Região Sudeste, encontra-se um efeito positivo do trabalho infantil sobre a educação diferencial. Isso pode significar que, no Sudeste, seja mais fácil para as crianças alocarem parte do seu tempo em trabalho e parte em estudo, tendo em vista as características das próprias ocupações disponíveis, sendo o trabalho uma forma de obter recursos para educação.

Quanto à evolução da restrição de crédito, os resultados do modelo de Mínimos Quadrados Ordinários estimação da educação diferencial, com dados empilhados de 1991 e 2000, apresentados na Tabela 3, indicam que houve um aumento da restrição de crédito para Brasil, entre o ano de 1991 e 2000, representando pelo coeficiente da interação da variável riqueza e da dummy para o ano 2000. Já os resultados das 
regressões por macrorregiões são bastante heterogêneos. Enquanto no Norte e Nordeste houve um aumento da restrição de crédito, no Sudeste houve um afrouxamento da mesma. Nas regiões Centro-Oeste e Sul, onde a restrição de crédito é maior, a variável de evolução dessa restrição não é significativa.

Tabela 3 - Educação Relativa (OLS) por Região (1991/2000)

\begin{tabular}{|c|c|c|c|c|c|c|}
\hline & Brasil & Norte & Nordeste & $\begin{array}{l}\text { Centro- } \\
\text { Oeste }\end{array}$ & Sudeste & Sul \\
\hline Riqueza*Ano & $0.050 * * *$ & $0.170 * * *$ & $0.196 * * *$ & -0.03 & $-0.073 *$ & 0.019 \\
\hline Riqueza & $0.169 * * *$ & 0.014 & $0.092 * * *$ & $0.300 * * *$ & $0.176^{* * *}$ & $0.220 * * *$ \\
\hline Sexo & $-0.089 * * *$ & $-0.096 * * *$ & $-0.112 * * *$ & $-0.067^{* *}$ & $-0.066 * * *$ & -0.036 \\
\hline Idade & $-0.007 * *$ & -0.007 & -0.005 & -0.014 & -0.008 & 0.003 \\
\hline $\begin{array}{l}\text { Ordem entre os } \\
\text { irmãos }\end{array}$ & $0.006 * * *$ & 0 & $0.004^{* * *}$ & $0.009 * * *$ & 0.003 & $0.010^{* * *}$ \\
\hline Filho único & $-0.048 * * *$ & -0.008 & $-0.049 *$ & -0.098 & -0.051 & -0.052 \\
\hline \multicolumn{7}{|l|}{$\begin{array}{l}\text { Variáveis do Chefe } \\
\text { de Família }\end{array}$} \\
\hline Está ocupado & $0.036^{*}$ & -0.015 & $0.070^{* *}$ & -0.018 & 0.037 & -0.011 \\
\hline $\begin{array}{l}\text { Total de horas traba- } \\
\text { lhadas }\end{array}$ & $-0.000^{*}$ & 0.001 & $-0.001^{* * *}$ & 0 & -0.001 & 0 \\
\hline Renda & 0 & 0 & 0 & 0 & 0 & 0 \\
\hline 1-4 anos de estudo & $0.019^{*}$ & 0.032 & $0.026^{*}$ & -0.032 & 0.015 & -0.033 \\
\hline 5-8 anos de estudo & $0.054^{* * *}$ & $0.081^{* *}$ & $0.110 * * *$ & 0.047 & 0.019 & -0.017 \\
\hline 9-11 anos de estudo & $0.096 * * *$ & $0.159 * *$ & $0.108^{* *}$ & 0.067 & 0.048 & $0.106^{*}$ \\
\hline $\begin{array}{l}12 \text { ou mais anos de } \\
\text { estudo }\end{array}$ & $0.145^{* *}$ & 0.031 & $0.345^{* *}$ & -0.122 & 0.156 & 0.053 \\
\hline Idade & -0.025 & 0.116 & -0.003 & -0.131 & -0.075 & $-0.169 *$ \\
\hline Idade $^{2}$ & 0.001 & -0.002 & 0 & 0.003 & 0.002 & $0.003^{*}$ \\
\hline Sexo & 0.015 & 0.006 & 0.023 & 0.106 & 0.019 & 0.025 \\
\hline $\begin{array}{l}\text { Não sabe ler e es- } \\
\text { crever }\end{array}$ & $-0.045^{* * *}$ & -0.017 & $-0.044^{* * *}$ & $-0.154^{* *}$ & -0.025 & $-0.074^{*}$ \\
\hline É empresário & $0.057^{*}$ & -0.002 & $0.090^{*}$ & 0.057 & 0.003 & 0.078 \\
\hline \multicolumn{7}{|l|}{$\begin{array}{l}\text { Variáveis do } \\
\text { Cônjuge }\end{array}$} \\
\hline Está ocupado & $0.029 *$ & 0.036 & $0.042 *$ & -0.032 & 0.056 & -0.027 \\
\hline $\begin{array}{l}\text { Total de horas trabal- } \\
\text { hadas }\end{array}$ & 0 & 0.001 & 0 & 0.001 & -0.001 & 0.001 \\
\hline Renda & 0 & 0 & 0 & 0 & $-0.000 * *$ & 0 \\
\hline 1-4 anos de estudo & $0.044^{* * *}$ & -0.001 & $0.053^{* * *}$ & -0.013 & $0.095^{* *}$ & -0.024 \\
\hline
\end{tabular}




\begin{tabular}{|c|c|c|c|c|c|c|}
\hline 5-8 anos de estudo & $0.113^{* * *}$ & $0.140 * * *$ & $0.122 * * *$ & 0.102 & $0.150 * * *$ & -0.012 \\
\hline 9-11 anos de estudo & $0.260 * * *$ & $0.359 * * *$ & $0.266^{* * *}$ & $0.272 * * *$ & $0.251^{* * *}$ & $0.125^{*}$ \\
\hline $\begin{array}{l}12 \text { ou mais anos de } \\
\text { estudo }\end{array}$ & $0.159 * *$ & -0.174 & $0.439 * *$ & -0.047 & 0.078 & $0.209 *$ \\
\hline Idade & $0.013 * * *$ & $0.009 * *$ & $0.010 * * *$ & $0.026 * * *$ & $0.017^{* * *}$ & $0.013^{* *}$ \\
\hline Idade $^{2}$ & $-0.000 * * *$ & 0 & $-0.000 * * *$ & $-0.000 * *$ & $-0.000 * * *$ & 0 \\
\hline $\begin{array}{l}\text { Não sabe ler e es- } \\
\text { crever }\end{array}$ & $-0.089 * * *$ & $-0.110 * * *$ & $-0.062 * * *$ & $-0.161^{* *}$ & $-0.091^{* *}$ & $-0.241 * * *$ \\
\hline É empresário & -0.043 & -0.394 & $0.445^{*}$ & $-0.846 * * *$ & 0.168 & $-0.362^{*}$ \\
\hline \multicolumn{7}{|l|}{ Variáveis da Família } \\
\hline Número de filhos & $-0.020 * *$ & 0.006 & $-0.027^{*}$ & -0.04 & -0.008 & $-0.048^{*}$ \\
\hline Número de filhas & -0.015 & 0.007 & $-0.024^{*}$ & -0.01 & -0.003 & -0.033 \\
\hline $\begin{array}{l}\text { Pelo menos um dos } \\
\text { filhos trabalha }\end{array}$ & $-0.083^{* * *}$ & $-0.071^{*}$ & $-0.126 * * *$ & -0.046 & -0.035 & -0.017 \\
\hline $\begin{array}{l}\text { Média de idade dos } \\
\text { filhos }\end{array}$ & $0.012 * * *$ & $0.012 * *$ & $0.015^{* * *}$ & 0.013 & 0.004 & $0.011 * *$ \\
\hline $\begin{array}{l}\text { Número de pessoas } \\
\text { na Família }\end{array}$ & -0.002 & -0.006 & 0.003 & 0.003 & 0.001 & -0.009 \\
\hline Dummies de Região & Sim & - & - & - & - & - \\
\hline Constante & -0.138 & $-1.743^{*}$ & -0.198 & 1.062 & 0.4 & 1.796 \\
\hline Observações & 65134 & 10613 & 28411 & 4618 & 13219 & 8273 \\
\hline
\end{tabular}

* significante a $10 \%$; ${ }^{* *}$ significante a $5 \%$; ${ }^{* *}$ significante a $1 \%$.

De um modo geral, as regressões apresentadas nas Tabelas 2 e 3 indicam a existência de uma certa heterogeneidade regional no que diz respeito aos efeitos da restrição de crédito sobre a educação relativa. A Figura 3 apresenta os resultados tanto para o racionamento de crédito em 2000 quanto para evolução da restrição entre 1991 e 2000, no nível microrregional.

Pelo Mapa A da Figura 3 é possível identificar uma concentração de microrregiões onde a restrição de crédito é ativa, quanto à educação infantil, no Nordeste. Além disso, há microrregiões com forte restrição ao crédito no Centro-Oeste, Norte e Sul. Por outro lado, no Sudeste, o efeito é significativo em apenas algumas poucas microrregiões.

Quanto à evolução da restrição de crédito, percebe-se, claramente, que houve um aumento da restrição de crédito concentrado nas microrregiões do Nordeste e no norte de Minas Gerais, notadamente regiões de menor desenvolvimento e menores níveis de renda per capita. 
Figura 3 - Análise Microrregional da Restrição de Crédito sobre a Educação Infantil

Mapa A: Restrição de Crédito sobre Educação Relativa (2000)

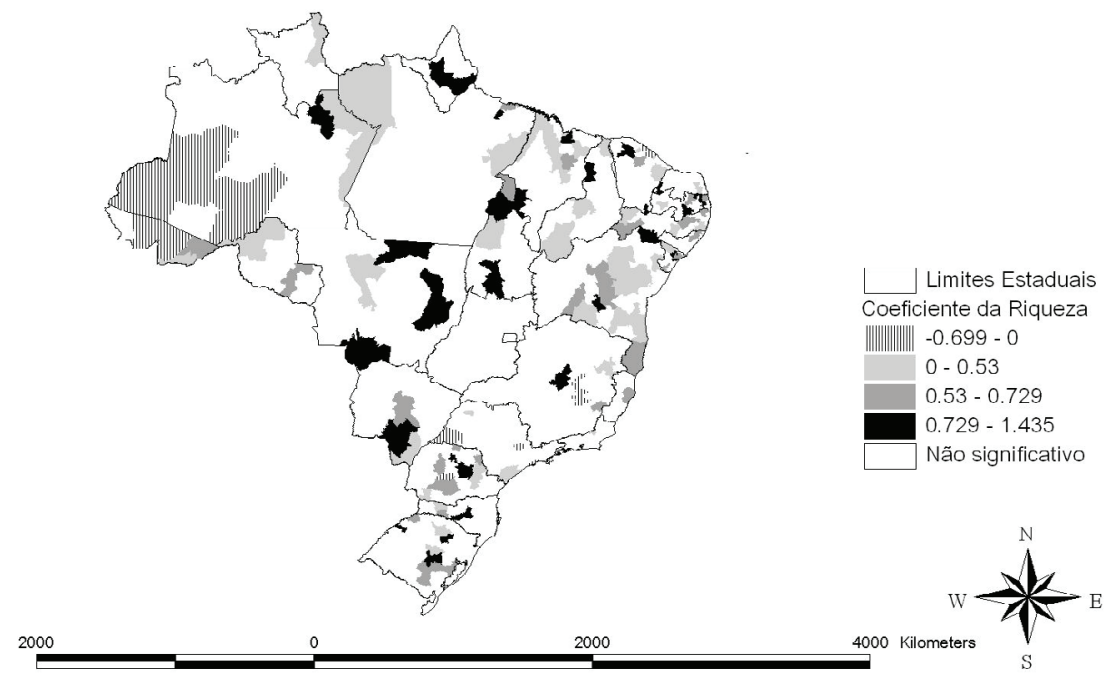

Mapa B: Evolução da Restrição de Crédito sobre Educação Relativa (1991/2000)

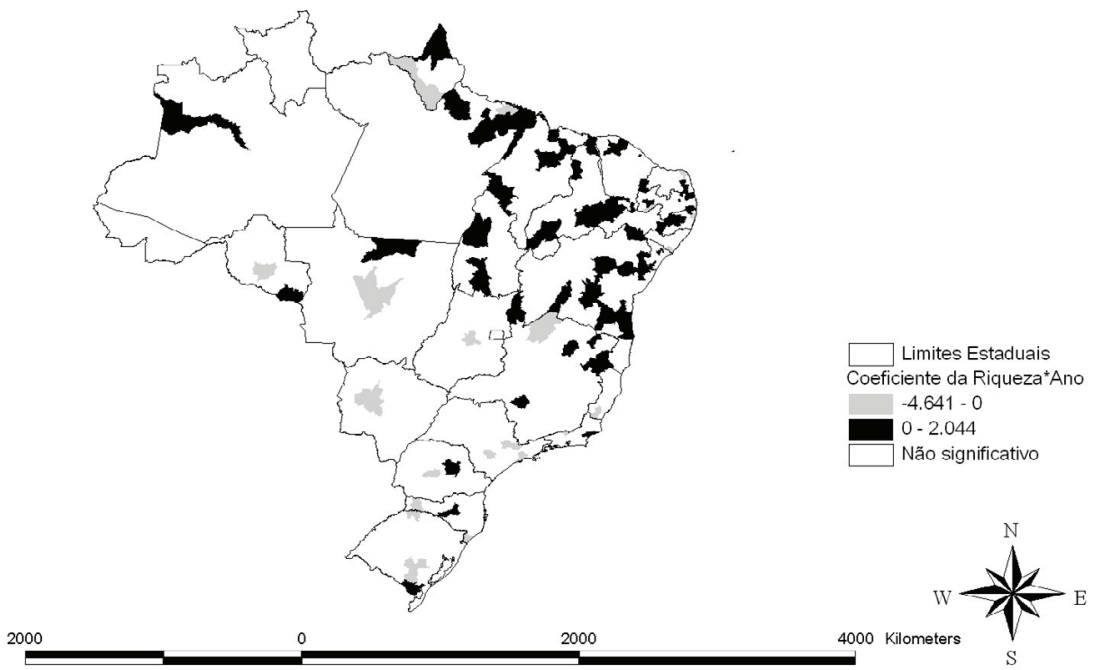

Fonte: Elaboração Própria. 


\subsection{Restrição de crédito e a probabilidade de ser empregador}

Tabela 4 - Probabilidade de ser Empresário (LPM) por Região (2000)

\begin{tabular}{|c|c|c|c|c|c|c|}
\hline & Brasil & Norte & Nordeste & $\begin{array}{l}\text { Centro- } \\
\text { Oeste }\end{array}$ & Sudeste & Sul \\
\hline Riqueza & $0.012^{* * *}$ & $0.010 * *$ & $0.008^{* * *}$ & $0.015^{* * *}$ & $0.020 * * *$ & $0.017 * * *$ \\
\hline 1-4 anos de estudo & 0 & 0 & 0 & 0 & 0 & -0.006 \\
\hline 5-8 anos de estudo & 0.002 & -0.002 & 0.001 & $0.006^{* *}$ & 0.003 & -0.003 \\
\hline 9-11 anos de estudo & $0.010 * * *$ & -0.001 & 0.004 & $0.018 * *$ & $0.012 * * *$ & 0.008 \\
\hline 12 ou mais anos de estudo & $0.038^{* * *}$ & $-0.018^{* *}$ & $0.066^{* *}$ & 0.065 & 0.039 & 0.011 \\
\hline Idade & $-0.004^{* *}$ & -0.003 & -0.004 & 0.003 & $-0.008^{*}$ & -0.002 \\
\hline Idade $^{2}$ & $0.000 * *$ & 0 & 0 & 0 & $0.000 * *$ & \\
\hline Não sabe ler e escrever & 0 & -0.002 & 0 & -0.001 & 0.001 & -0.003 \\
\hline Sexo & $0.006 * *$ & 0.009 & 0.003 & -0.014 & $0.008^{* * *}$ & $0.009 * * *$ \\
\hline \multicolumn{7}{|l|}{ Variáveis do Cônjuge } \\
\hline Está ocupado & 0 & 0.002 & 0.001 & -0.007 & 0.002 & 0.001 \\
\hline Renda & 0 & 0 & 0 & 0 & $-0.000 * *$ & \\
\hline $1-4 \mathrm{a}$ & -0.002 & 0 & -0.001 & 0.001 & -0.002 & $-0.014^{*}$ \\
\hline 5-8 anos de estudo & -0.001 & 0.001 & 0 & 0.001 & -0.002 & $-0.014^{*}$ \\
\hline 9-11 anos de estudo & $0.010^{* * *}$ & 0.003 & $0.006 * *$ & $0.022 * *$ & $0.007 * *$ & 0.006 \\
\hline 12 ou mais anos de estudo & $0.032^{* * *}$ & 0.051 & -0.007 & 0.027 & $0.055 * *$ & 0.016 \\
\hline Idade & 0 & $0.001 * *$ & 0 & 0 & $0.000 * *$ & \\
\hline Idade $^{2}$ & $-0.000 * *$ & $-0.000 * *$ & 0 & 0 & $-0.000 * *$ & \\
\hline Não sabe ler e escrever & -0.001 & -0.003 & -0.001 & 0.004 & -0.001 & $-0.012^{* *}$ \\
\hline \multicolumn{7}{|l|}{ Variáveis da Família } \\
\hline Número de filhos & $-0.006 * * *$ & $-0.009 * *$ & $-0.003^{*}$ & $-0.014^{* *}$ & $-0.006^{* *}$ & $-0.012 * * *$ \\
\hline Número de filhas & $-0.006 * * *$ & $-0.008^{* *}$ & $-0.003 * *$ & $-0.013^{* *}$ & $-0.006^{* *}$ & $-0.010^{* *}$ \\
\hline $\begin{array}{l}\text { Pelo menos um dos filhos } \\
\text { trabalha }\end{array}$ & 0 & 0.002 & -0.002 & -0.005 & 0.006 & -0.004 \\
\hline Média de idade dos filhos & $-0.000^{*}$ & $-0.001 * * *$ & 0 & 0.001 & 0 & \\
\hline Número de pessoas na Família & $0.006^{* * *}$ & $0.008^{* *}$ & $0.003^{* *}$ & $0.012^{* *}$ & $0.005^{*}$ & $0.011^{* * *}$ \\
\hline \multicolumn{7}{|l|}{ Atividade do Cônjuge } \\
\hline Cônjuge é empresário & $0.486 * * *$ & $0.410 * *$ & $0.528 * * *$ & $0.712 * * *$ & $0.390 * *$ & $0.572 * * *$ \\
\hline $\begin{array}{l}\text { Cônjuge está no mesmo setor } \\
\text { de atividade do chefe }\end{array}$ & 0 & -0.002 & -0.001 & 0.003 & -0.001 & 0.004 \\
\hline Dummies de Atividade & Sim & Sim & Sim & Sim & Sim & Sim \\
\hline Dummies de Região & Sim & - & - & - & - & \\
\hline Constante & 0.026 & -0.006 & 0.046 & -0.064 & 0.069 & 0.001 \\
\hline Observações & 104278 & 13399 & 44175 & 7807 & 23854 & 15043 \\
\hline
\end{tabular}

* significante a $10 \%$; ** significante a $5 \% ; * * *$ significante a $1 \%$ 
Os resultados da estimação do modelo de probabilidade linear para o efeito da riqueza sobre a probabilidade dos chefes entre 20 e 29 anos serem empresários são apresentados na Tabela 4. Nessas regressões são incluídos, além da variável riqueza, dummies de região (para a regressão do Brasil) e setor de atividade e outras variáveis de controle, referentes a características individuais, do cônjuge, da família e da atividade do cônjuge.

A inclusão das dummies de região e setor de atividade objetiva controlar para fatores específicos, não observados, da região e da atividade que pode influenciar a oferta e demanda de crédito, isto porque os custos da atividade empresarial podem variar de uma localidade para outra, bem como segundo os diferentes tipos de empreendimentos. Além disso, é comum que existam linhas de crédito específicas para determinadores setores econômicos, bem como para regiões específicas, como é o caso, por exemplo, dos fundos constitucionais de financiamento.

De outro lado, a decisão do agente em se tornar um empresário é fortemente influenciada pelo talento ou capacidade empresarial, que torna o empresário menos dependente do financiamento, pois empresários mais qualificados irão demandar menos capital para iniciar um negócio. Tal relação ocorre ou porque talento e capital atuam como substitutos ou como complementares, de modo que empresários mais talentosos conseguem produzir mais com uma mesma quantidade de capital (Paulson e Townsend, 2001).

Em todas as regressões, tanto para o Brasil, como para todas as macrorregiões, o coeficiente da variável riqueza mostrou-se significativo e positivo, indicando uma provável existência de falhas no mercado de crédito. A Região Sudeste aparece como a macrorregião com maior impacto de um aumento da riqueza sobre a probabilidade de ser empregador.

É curioso que o efeito da escolaridade sobre a decisão de ser empregador é distinto para o Brasil e os cinco grupos de região considerados. Enquanto que, no Brasil, a escolaridade tem importância sobre a probabilidade de ser empresário apenas para os que possuem mais de 9 anos de estudo, no Centro-Oeste, o efeito aparece para os que tem de 5 a 8 e de 9 a 11 anos de estudo.

De outro lado, a probabilidade do chefe ser empresário é menor quanto maior for o número de filhos e filhas, isto porque, como as deci- 
sões intra-familiares são relacionadas entre si, um chefe de família com mais filhos, tenderá a arriscar menos, tendo em vista os investimentos necessários em alimentação, educação e saúde dos filhos. De modo complementar, quando há um maior número de pessoas na família, contribuindo para o sustento do domicílio, há um aumento na probabilidade do chefe ser empresário.

Outro resultado interessante refere-se ao coeficiente da dummy que controla para o fato do cônjuge também ser empresário. Em todas as regiões há um efeito positivo e bastante significativo dessa variável, indicando que o chefe se beneficia da experiência do cônjuge na atividade empresarial.

Embora os resultados apresentados na Tabela 4 indiquem a existência de falhas no mercado de crédito em todas as macrorregiões, é necessária uma investigação dessa homogeneidade em níveis regionais menores. A Figura 4 apresenta o mapeamento do coeficiente da variável riqueza para as microrregiões.

Figura 4 - Análise Microrregional da Restrição de Crédito sobre a Probabilidade de ser Empresário (2000)

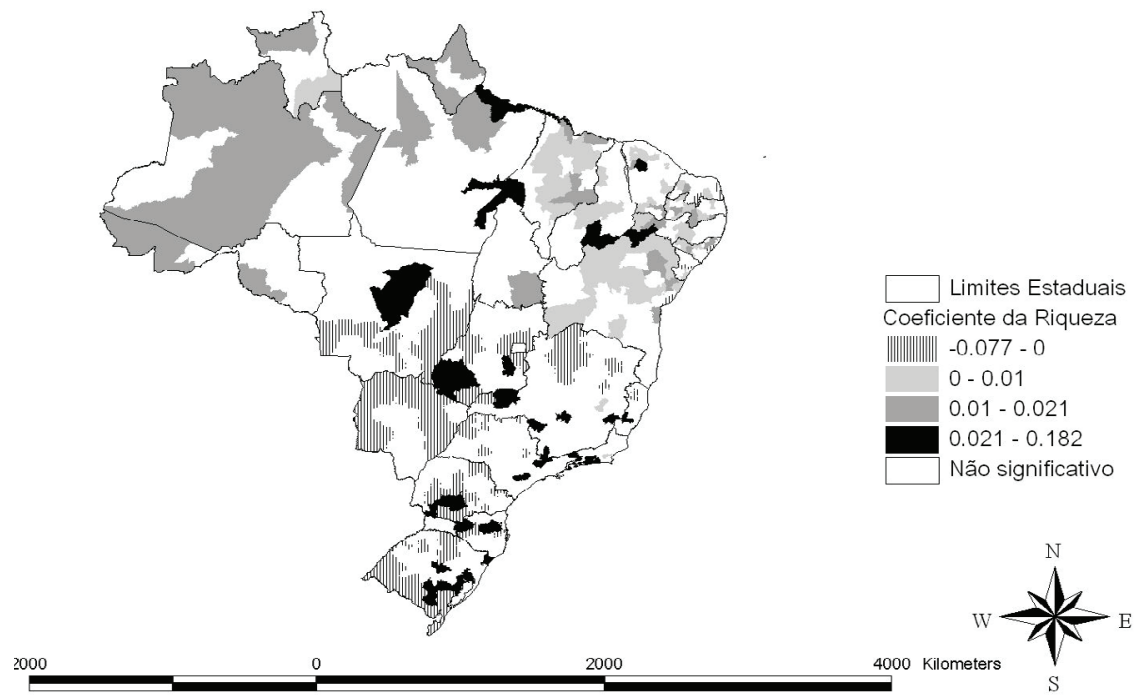

Fonte: Elaboração Própria. 
Verifica-se que há uma concentração de microrregiões onde a restrição de crédito é ativa no Nordeste e no extremo norte do país, embora haja pontos espalhados de restrição de crédito acentuada em todas as macrorregiões. Tal resultado é apenas uma forma preliminar de verificar a restrição de crédito e que deve ser objeto de investigações mais detalhadas.

\subsection{Restrição de Crédito e Indicadores Sócio-Econômicos}

A heterogeneidade regional dos resultados encontrados nas seções anteriores (Figuras 3 e 4), tanto no que se refere aos efeitos da restrição de crédito sobre educação como sobre a decisão do chefe em ser um empresário, torna importante uma investigação da correlação entre os coeficientes encontrados e indicadores sócio-econômicos e de produtividade. A Tabela 5 apresenta algumas correlações com indicadores selecionados.

Tabela 5 - Correlação entre Coeficientes da Restrição de Crédito e Indicadores Sociais e de Produtividade

\begin{tabular}{l|r|r|r}
\hline & $\begin{array}{c}\text { Restrição de } \\
\text { Crédito sobre } \\
\text { a Educação } \\
\text { Infantil }\end{array}$ & $\begin{array}{c}\text { Evolução da } \\
\text { Restrição de } \\
\text { Crédito sobre a } \\
\text { Educação Infantil }\end{array}$ & $\begin{array}{c}\text { Restrição de } \\
\text { Crédito sobre a } \\
\text { Probabilidade de } \\
\text { ser Empresário }\end{array}$ \\
\hline $\begin{array}{l}\text { Indicadores Sociais e } \\
\text { Produtividade }\end{array}$ & 0.0177 & $\mathbf{- 0 . 3 4 9 9 * * *}$ & $\mathbf{0 . 1 2 8 7 *}$ \\
\hline Média da Renda Familiar Per & 0.0128 & $\mathbf{- 0 . 3 2 0 5 * * *}$ & 0.0441 \\
Capita & -0.0575 & -0.0044 & -0.0049 \\
Média de Anos de Estudo & $\mathbf{0 . 2 0 2 1 * *}$ & $-\mathbf{0 . 2 3 8 5 * *}$ & -0.0013 \\
Índice de Gini & $\mathbf{0 . 3 4 4 * * *}$ & 0.0703 & -0.0388 \\
$\begin{array}{l}\text { Percentual de Crianças que } \\
\text { Sabem ler e Escrever }\end{array}$ & -0.0185 & -0.1084 & -0.1142 \\
Percentual de Crianças na Escola & -0.0095 & -0.1524 & -0.0063 \\
Agências Bancárias por mil & 0.1456 & -0.035 & 0.0542 \\
Habitantes & Urbanização & & \\
Produtividade Agrícola & & & \\
\hline
\end{tabular}

*significativo a $10 \%$, ** significativo a $5 \%,{ }^{* * *}$ significativo a $1 \%$ Fonte: Elaboração Própria a partir de dados dos Censos Demográficos 1991/2000 (IBGE), COSIF/BACEN. 
É possível verificar, analisando os dados da Tabela 5, uma correlação positiva e significativa entre o percentual de crianças que sabem ler e escrever e o percentual de crianças na escola com a restrição de crédito sobre a educação infantil. Isso significa apenas que a restrição tende a ser maior onde a população analisada é maior. Já para o coeficiente da evolução da restrição de crédito, há uma correlação negativa com a média da renda familiar per capita, com a média de anos de estudo e com o percentual de crianças que sabem ler e escrever, o que confirma o fato de que o aperto no crédito teria sido maior em regiões de menor desenvolvimento, como é o caso do Nordeste.

No que se refere ao efeito restrição de crédito sobre a probabilidade de o chefe ser empresário, verifica-se apenas uma correlação positiva dessa com a média de renda familiar per capita. Não por caso, os coeficientes da variável riqueza para as regiões Sudeste e Sul, regiões com maiores rendimentos per capita, na regressão da Tabela 4, eram os mais elevados.

Na seção seguinte, é investigada a relação entre a restrição de crédito encontrada a partir do comportamento individual e a média de crédito formal concedido por microrregião.

\section{Crédito Formal}

\subsection{Crédito Rural}

O objetivo dessa seção é apresentar uma análise exploratória do crédito formal concedido para atividades rurais entre de 1991 e 2000 e de sua relação com os resultados das seções anteriores. Para tanto, são utilizados dados do Plano Contábil das Instituições do Sistema Financeiro Nacional (COSIF), disponibilizados pelo Banco Central do Brasil. Os dados originais do COSIF são apresentados em séries mensais por município. As informações aqui apresentadas referem-se a médias anuais para os anos de 1991 e 2000, por microrregiões geográficas, de modo a se ter uma série comparável com os dados dos Censos Demográficos.

Como o foco do artigo é a restrição de crédito no Brasil rural, foram selecionadas apenas as categorias de financiamento direcionadas a atividades do meio rural, bem como o valor total de operações de crédito 
realizadas, que inclui, além das categorias selecionadas, outras operações não direcionadas especificamente ao setor, como empréstimos e títulos descontados, financiamentos imobiliários, entre outros.

Na Figura 5 é representada a evolução da média dos financiamentos concedidos $^{2}$ por tipo de categoria para os anos de 1991 e 2000. De 1991 a 2000, houve um aumento do volume de financiamento concedido para todas as categorias selecionadas, excetuando-se a agroindústria, onde houve queda do volume de crédito concedido.

Figura 5 - Evolução do Financiamento para Atividades Rurais

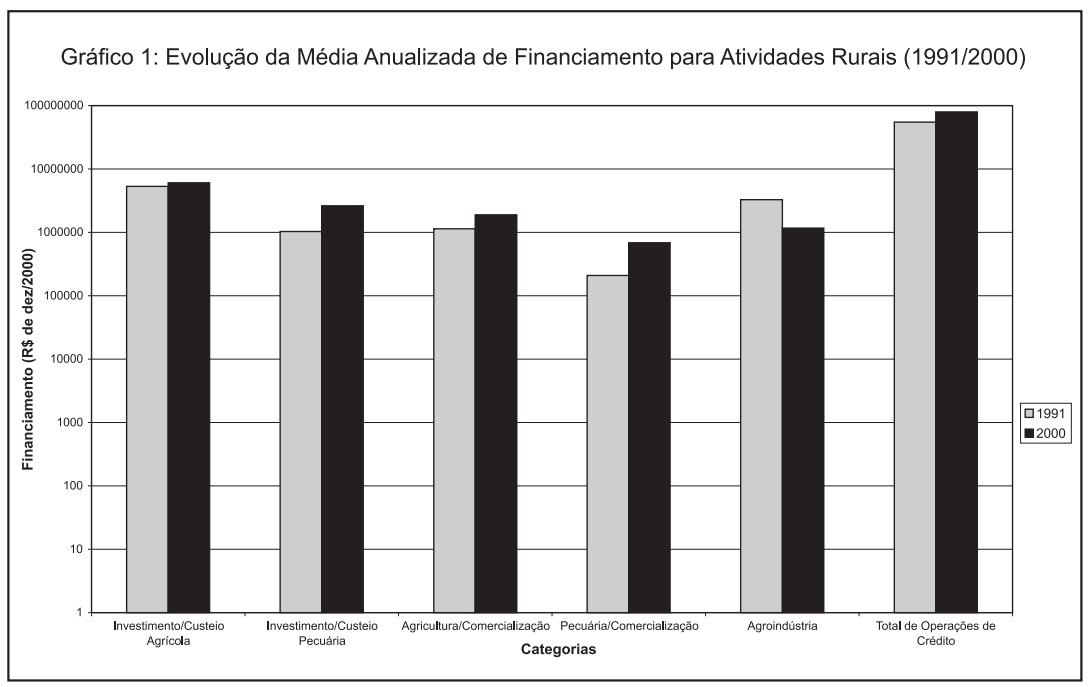

Fonte: COSIF/BACEN.

Entretanto, a evolução do crédito formal concedido para atividades rurais não se deu de forma homogênea entre as microrregiões. A Figura 6 é uma representação tanto da distribuição das operações de crédito em 2000 como do crescimento regional das operações de crédito em 1991 e 2000. Analisando o Mapa A, é possível constatar que existe uma concentração dos financiamentos rurais no centro-sul do país (áreas mais escuras do mapa), com áreas mais claras, com menor média anual para o valor das operações de crédito, no Norte e Nordeste.

\footnotetext{
${ }^{2}$ Dados deflacionados pelo IGP-M e apresentados em escala logarítmica.
} 
Figura 6 - Distribuição Regional do Total de Operações de Crédito Situação em 2000 e Evolução 1991/2000
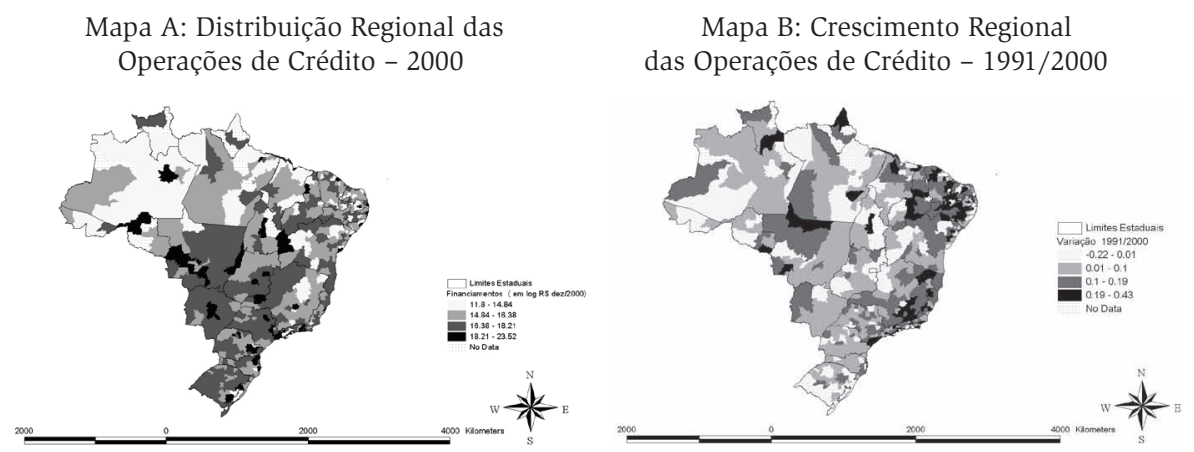

Fonte: COSIF/BACEN.

Por outro lado, o Mapa B da Figura 6, denota que houve um maior crescimento do volume das operações de crédito em microrregiões mais concentradas no Nordeste e leste do país, de forma mais geral, o que pode ser um indício de desconcentração regional dos financiamentos.

A Figura 7 apresenta o mapeamento da distribuição regional dos financiamentos agrícolas por categorias, em volume ( $\mathrm{R} \$$ ) e em volume (R\$) por área plantada (ha). O Mapa A enfatiza a concentração dos financiamentos para investimento e custeio na agricultura no Centro-Oeste, tendência que é reforçada quando se analisam os financiamentos por área plantada (Mapa B). Quantos aos financiamentos para a agroindústria, mais uma vez, a concentração se dá no Centro-Oeste e em microrregiões pulverizadas no Nordeste e Sul, além de outras microrregiões mais esparsas. Contudo, os Mapas C e D indicam uma tendência de desconcentração maior desses investimentos em direção ao leste do Brasil.

Para os financiamentos direcionados à pecuária, é mais evidente a existência de uma concentração ao longo e no entorno de uma linha diagonal que vai do Mato Grosso do Sul até a região Nordeste, isso ocorre, especialmente, para os financiamentos para investimento e custeio na pecuária (Mapas A, B da Figura 8). Ao contrário do que ocorre na agricultura, essa tendência de concentração parece estar sendo reforçada, como sugerem os Mapas E e F.

A Figura 8 traz, ainda, a distribuição regional dos financiamentos para a comercialização da pecuária, cujos financiamentos concedidos são menores e concentrados no centro-sul. 
Figura 7 - Distribuição Regional do Financiamento Agrícola por Categoria - Situação em 2000 e Evolução 1991/2000

Mapa A: Financiamentos para Investimentos e Custeio na Agricultura - 2000

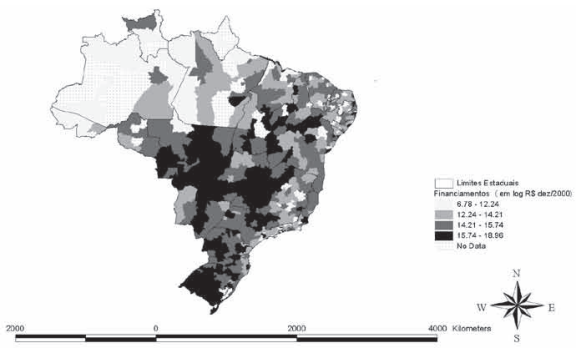

Mapa C: Financiamentos para Agroindústria 2000

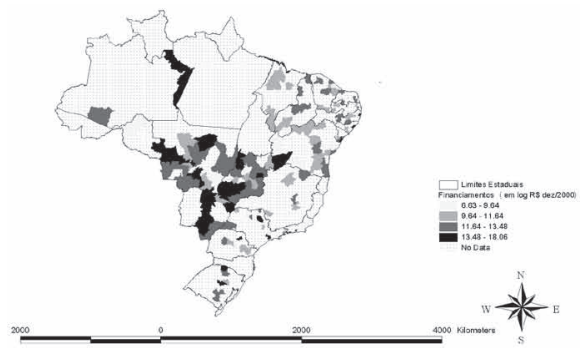

Mapa B: Financiamentos para Investimento e Custeio na Agricultura por Área Plantada - 2000

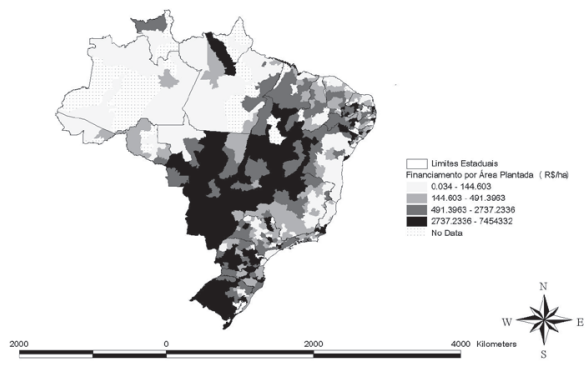

Mapa D: Crescimento Anual do Financiamento para Investimentos e Custeio na Agricultura $1991 / 2000$

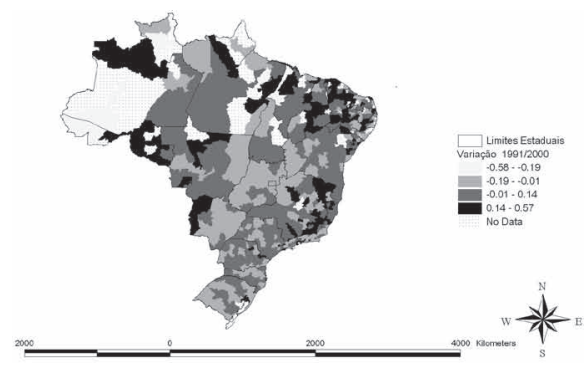

Mapa E: Crescimento Anual do Financiamento para Investimentos e Custeio na Agricultura por Área Plantada - 1991/2000

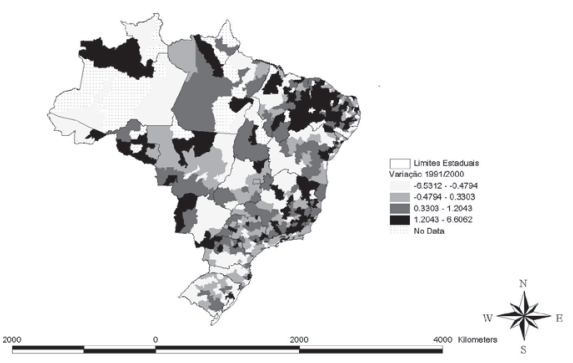

Fonte: COSIF/BACEN. 
Figura 8 - Distribuição Regional do Financiamento para Pecuária por Categoria - Situação em 2000 e Evolução 1991/2000

Mapa A: Financiamentos para Investimento e Custeio na Pecuária - 2000

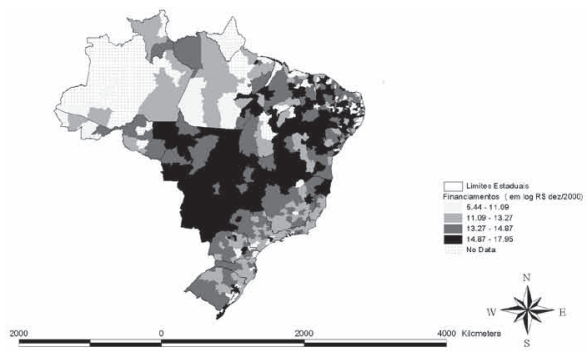

Mapa C: Financiamento para Comercialização da Pecuária - 2000

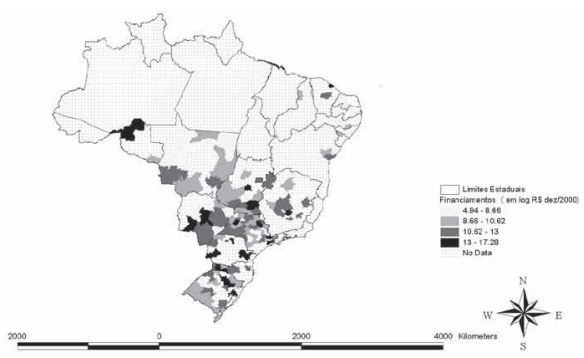

Mapa E: Crescimento Anual do Financiamento para Investimento e Custeio na Pecuária - 1991/2000

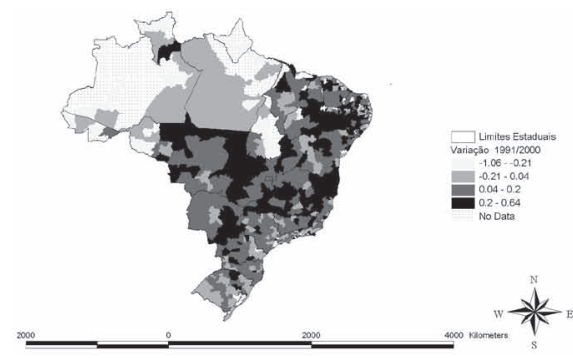

Mapa B: Financiamento para Investimento e Custeio na Pecuária por Efetivo de Rebanho - 2000

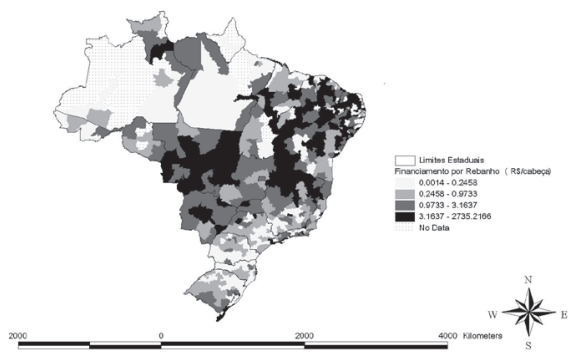

Mapa D: Financiamento para Comercialização da Pecuária por Efetivo de Rebanho - 2000

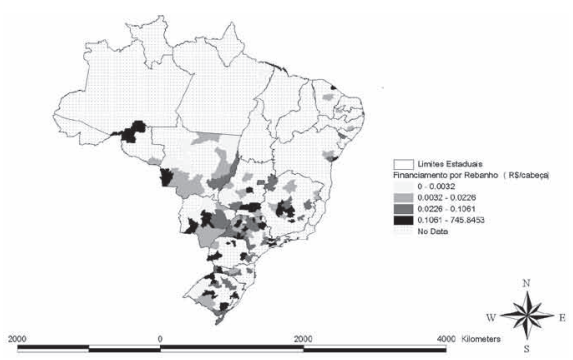

Mapa F: Crescimento Anual do Financiamento para Invest./ Custeio na Pecuária por Efetivo - 1991/2000

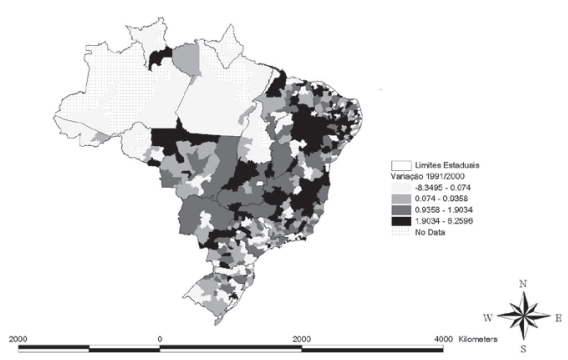

Fonte: COSIF/BACEN 
De um modo geral, pode-se afirmar que o Centro-Oeste parece estar se beneficiando mais dos financiamentos ou linhas de crédito disponíveis para investimentos, custeio e financiamento de atividades rurais, havendo indícios de um movimento favorável em direção à região Nordeste. No caso do Centro-Oeste, tal concentração pode estar relacionada com a concentração de grandes produtores, sobretudo de grãos e gado, na região. Já no Nordeste, o fluxo dos financiamentos pode estar acompanhando algum tipo de incentivo fiscal para áreas menos desenvolvidas, o que não significa que tais financiamentos estejam sendo direcionados para a população mais pobre, com maiores restrições de crédito.

A Tabela 6 apresenta, a exemplo do que foi realizado na seção anterior com os coeficientes de restrição de crédito, a correlação dos financiamentos de crédito formal, por categoria com indicadores sociais e de produtividade. As correlações significativas são destacadas em negrito.

O volume total das operações de crédito é positivamente correlacionado com a média da renda familiar per capita (0.466), com a média de anos de estudo (0.524), com o percentual de crianças que sabem ler e escrever (0.367), com o percentual de crianças na escola (0.247), com o total de agências bancárias por mil habitantes (0.213), com a taxa de urbanização (0.674) e com a produtividade agrícola $(0.210)$, todos indicadores com relação direta com o nível de desenvolvimento. Há, portanto, um forte indício, de que o crédito, de um modo geral, tende a ser direcionado para as regiões mais desenvolvidas.

De outro lado, quando se observa a evolução das operações de crédito, entre 1991 e 2000, há uma relação negativa com esses indicadores, o que pode estar delineando uma tendência à atenuação dessas disparidades. Tal tendência aparece, de modo semelhante, quando se observa a evolução do financiamento para investimento e custeio na agricultura. Já os financiamentos para pecuária sugerem um reforço à concentração do crédito.

A tendência à existência de uma concentração do crédito em regiões mais desenvolvidas surge, de forma acentuada, também, quando se analisa o investimento para a agroindústria. Há uma correlação forte do financiamento para a agroindústria com a média da renda familiar per capita (0.244), com a média de anos de estudo (0.325), com o número de agências bancárias por mil habitantes (0.183) e com a taxa de urbanização (0.284). 


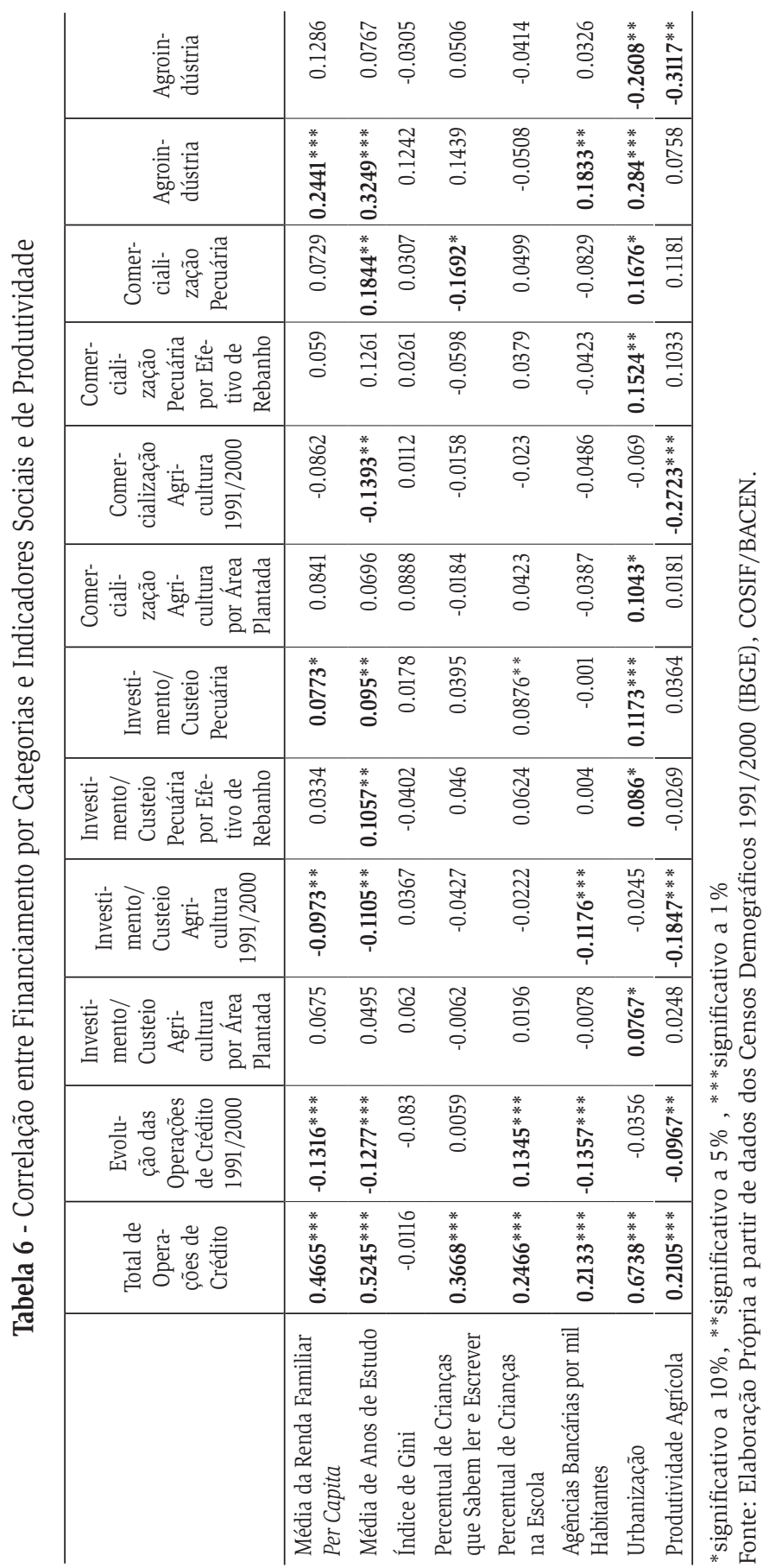




\subsection{Programa de fortalecimento da agricultura Familiar (PRONAF)}

O PRONAF foi criado em 1995 com o intuito de oferecer condições diferenciadas de acesso ao crédito para agricultores familiares. O programa é quase que totalmente financiado por recursos públicos, originados do FAT (Fundo de Amparo ao Trabalhador), do Orçamento Geral da União e dos Fundos Constitucionais de Financiamento. Atualmente as taxas de juros para os agricultores familiares variam entre $3.0 \%$ e $7.25 \%$ ao ano, com prazos para pagamento de até oito anos, variando conforme a capacidade de pagamento do cliente.

Dados recentes sobre evolução anual do valor total de recursos financiados pelo PRONAF e do número de contratos firmados indicam que no período de 2000 a 2004 houve um aumento significativo desses empréstimos. Os dados da Figura 9 evidenciam tal tendência.

Figura 9 - Evolução de Financiamentos do PRONAF

Gráfico 1: Valor dos Financiamentos do PRONAF

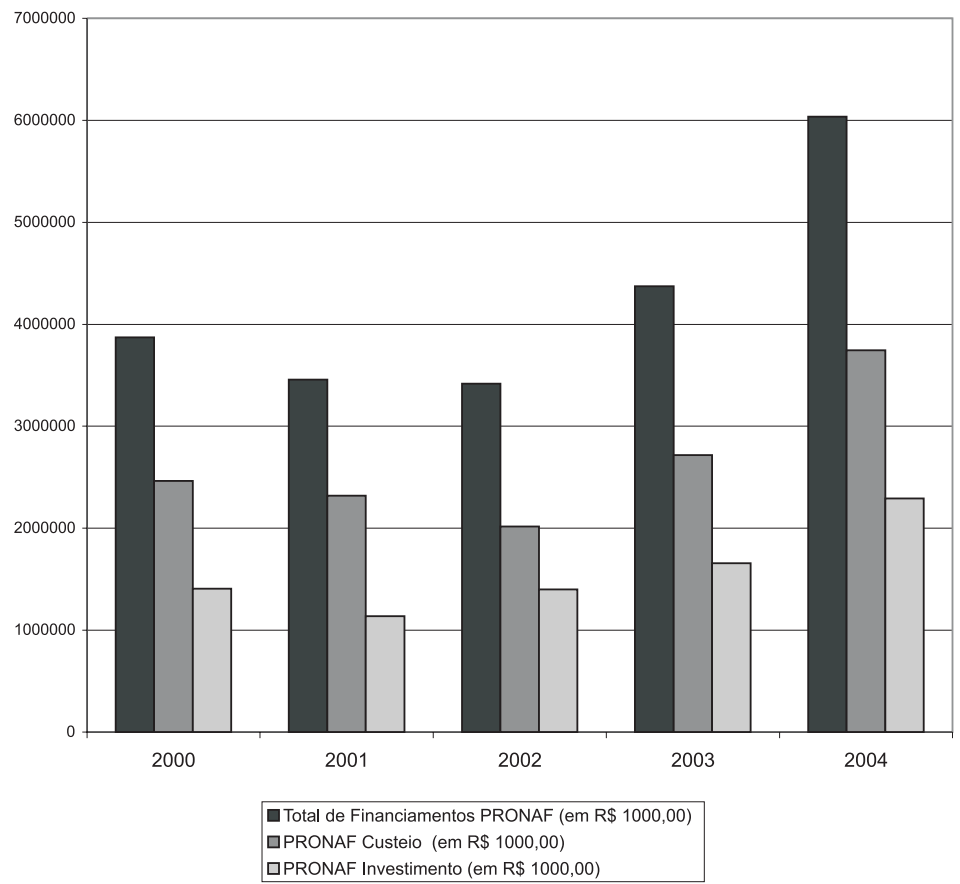


Gráfico 2: Contratos de Financiamentos do PRONAF

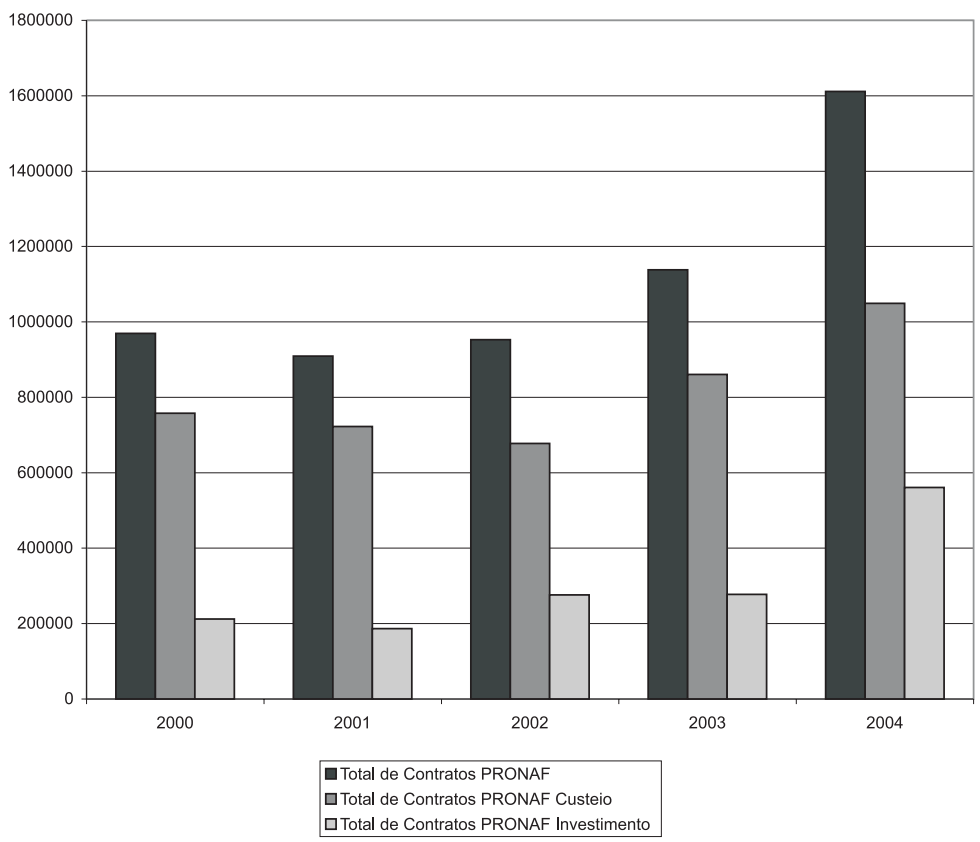

Fonte: PRONAF/MDA.

Em 2000, o total de recursos disponibilizados pelo PRONAF era de cerca de 3,9 bilhões de reais, sendo 2,5 bilhões destinados a empréstimos para operações de custeio e 1,4 para investimentos, incluindo entre os itens financiáveis, desde a compra de caminhões e tratores até obras de irrigação e eletrificação rural. Em 2004, os empréstimos do PRONAF alcançaram a cifra de 6 bilhões de reais $(3,7$ bilhões de reais para custeio e 2,3 para investimentos), representando um aumento em torno de $56 \%$ dos recursos do programa. Já o total de contratos passou de cerca de 970 mil para 1,6 milhões.

Contudo, embora o PRONAF tenha como área de abrangência todo o território nacional, a distribuição de recursos ou de empréstimos concedidos não ocorre de forma homogênea quando se analisa os montantes dos financiamentos e o total de contratos por microrregião. Pelo Mapa A da Figura 10, é possível perceber uma concentração de recursos do PRONAF na modalidade custeio, em 2000, nas porções leste e sul do território nacional, especificamente numa faixa que vai do interior 
nordestino à região Sul do país. Além dessa mancha escura mais ampla, percebem-se algumas microrregiões no Centro-Oeste e Norte, com valores mais altos de financiamentos recebidos.

Figura 10 - Distribuição Regional do PRONAF para Custeio e Investimento

$$
-2000 / 2004
$$

Mapa A: Financiamento do PRONAF para Custeio em 2000

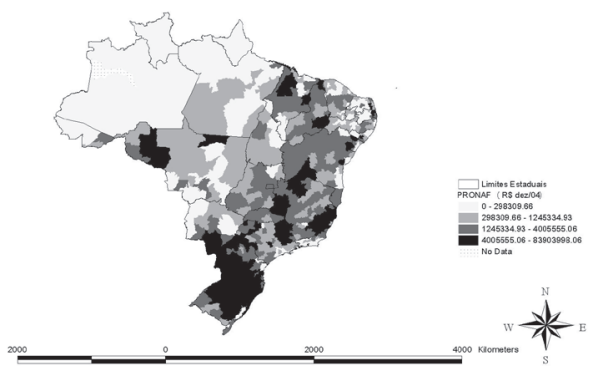

Mapa C: Variação PRONAF Custeio 2000/2004

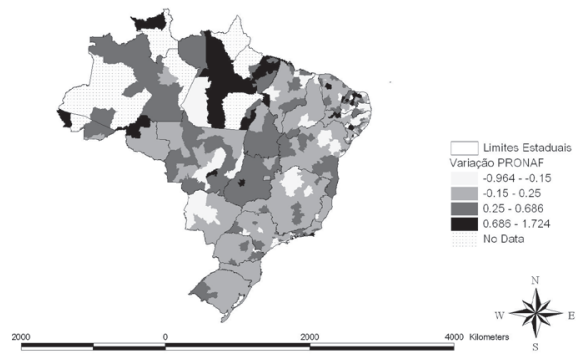

Mapa E: Financiamento do PRONAF para Investimento em 2004

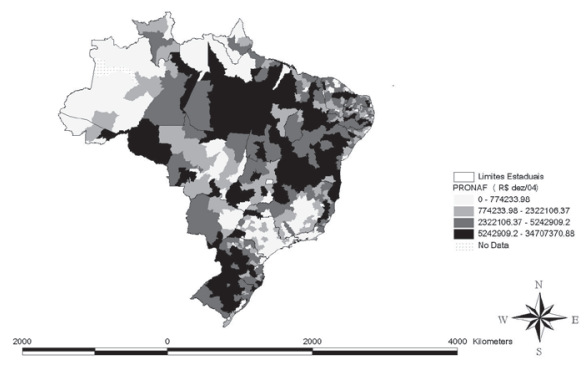

Mapa B: Financiamento do PRONAF para Custeio em 2004

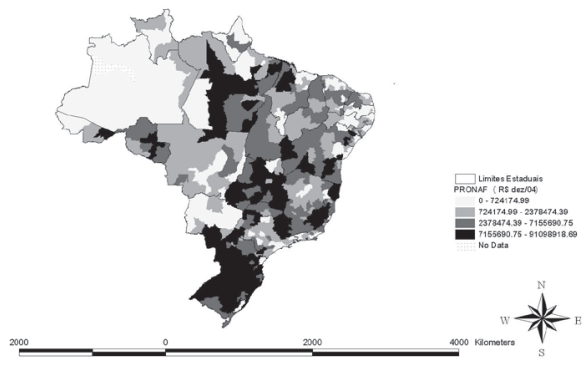

Mapa D: Financiamento do PRONAF para Investimento em 2000

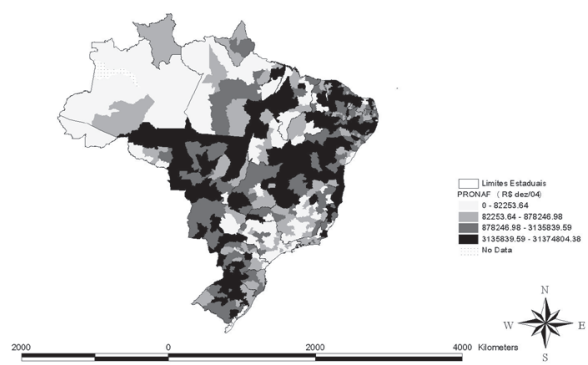

Mapa F: Variação PRONAF Investimento $2000 / 2004$

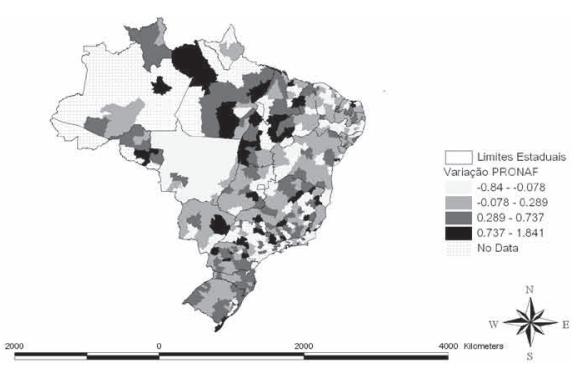

Fonte: PRONAF/MDA. 
O comparativo dos Mapas A e B, da Figura 10, aponta para uma tendência de desconcentração de recursos do Nordeste em direção ao Norte e Centro-Oeste, especificamente, na direção de microrregiões do Pará, Tocantins e Goiás (Mapa C).

Quanto aos recursos para investimentos, o padrão é bastante distinto, mas se mantém mais ou menos constante entre 2000 e 2004 (Mapas D e E). O que se observa é uma mancha clara nas microrregiões do Sudeste, do Mato Grosso do Sul e do extremo Norte, com valores de empréstimos concedidos pelo PRONAF investimento bem abaixo do restante do país. A análise do Mapa F retrata um quadro de maior heterogeneidade quanto à evolução dos recursos de empréstimos para investimento comparativamente àqueles de custeio, embora haja uma evolução acentuadamente mais forte em uma grande área do Pará e Roraima, no Norte do país.

Em síntese, pode-se afirmar que, de 2000 para 2004, os financiamentos do PRONAF, que eram muito direcionados para as regiões Nordeste e Sul, sofreram uma desconcentração em direção a algumas microrregiões do Norte, especialmente, do Pará e Tocantins.

Numa tentativa de correlacionar a alocação espacial dos empréstimos desse programa com o nível de desenvolvimento das regiões, a Tabela 7, apresenta a correlação de alguns indicadores sócio-econômicos com os valores dos financiamentos concedidos para custeio e investimento.

Para o PRONAF na modalidade custeio, verifica-se que, tanto para o ano 2000 como para 2004, existe um indício forte de correlação positiva entre o total de financiamentos e indicadores associados a um maior nível de desenvolvimento. Há, por exemplo, uma correlação positiva e fortemente significativa entre tais financiamentos e a renda familiar per capita média $(0,22$ e 0,26$)$, a média de anos de estudo $(0,28$ e 0,32) e o número de agências bancárias por mil habitantes $(0,28$ e 0,32). Além disso, verifica-se uma correlação positiva com a produtividade agrícola e negativa com o índice de Gini. Obviamente, como essa é uma análise meramente exploratória, é difícil identificar qual a relação de causalidade existente entre tais indicadores e os empréstimos do PRONAF. O programa pode não necessariamente estar sendo direcionado para regiões mais desenvolvidas ou menos desiguais, mas o fato de residir em tais regiões pode significar um acesso mais fácil a esse mecanismo de financiamento. 


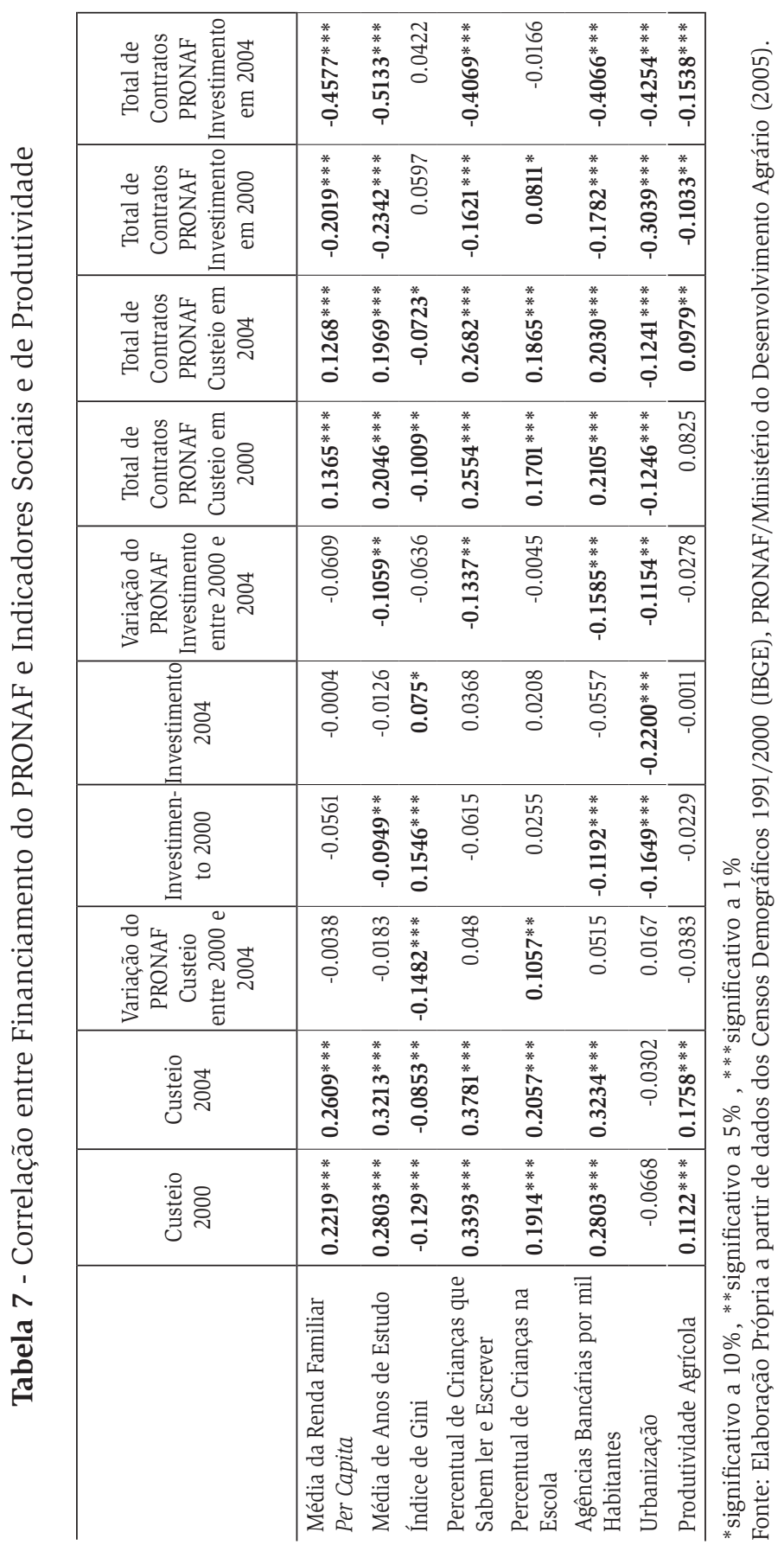


Por outro lado, deve-se enfatizar o comportamento distinto dos empréstimos do PRONAF destinados a investimento. Analisando os recursos aplicados em 2000, há uma correlação negativa com a média de anos de estudo $(-0,095)$, com o número de agências bancárias por mil habitantes $(-0,119)$ e com a taxa de urbanização $(-0,165)$. Há um indício, portanto, de que os recursos do PRONAF investimento tenham um peso maior em regiões onde o acesso ao crédito é mais difícil. Tal tendência parece se manter ao longo do período compreendido entre 2000 e 2004, pelo menos quando se observam as correlações entre a variação do PRONAF investimento no período e os indicadores sócioeconômicos selecionados, há uma correlação negativa e significativa com o percentual de crianças na escola $(-0,13)$, com a média de anos de estudo $(-0,10)$, com a taxa de urbanização $(-0,16)$ e com a produtividade agrícola $(-0,15)$. Essa situação pode significar que o PRONAF investimento esteja sendo direcionado exatamente para pessoas que estão mais restritas ao crédito.

\subsection{Restrição de crédito e financiamento para atividades rurais}

Resta, portanto, testar a correlação entre os indicadores de crédito formal e o crédito informal, construídos a partir das regressões da seção 4. A Tabela 8 apresenta os coeficientes de correlação e os respectivos níveis de significância.

Há uma correlação positiva (0.22), ao nível de significância de $5 \%$, entre o efeito restrição de crédito sobre a educação infantil e a evolução das operações de crédito entre 1991 e 2000, ao mesmo tempo, em que existe uma relação negativa entre esse efeito e o financiamento para investimento/custeio na pecuária. O que se pode inferir é que houve um aumento maior do financiamento nas regiões mais restritas ao crédito. De outro lado, quando se analisam as correlações da evolução da restrição de crédito sobre a educação infantil e o crédito formal, verifica-se que o aumento da restrição foi maior nas microrregiões onde o total das operações de crédito é menor.

Contudo, há uma relação positiva entre o coeficiente da evolução da restrição de crédito e o da evolução do total de operações de crédito, de modo que, o aperto de crédito de 1991/2000 é maior onde houve um 
maior aumento das operações de crédito. Tal correlação pode ser um indício de que o aumento do crédito tenha sido direcionado para grupos específicos da população, não atingindo os pais entre 20 e 29 anos residentes em domicílios rurais.

Tabela 8 - Correlação entre Coeficientes da Restrição de Crédito e Crédito Formal

\begin{tabular}{|c|c|c|c|}
\hline & $\begin{array}{c}\text { Restrição } \\
\text { de Crédito } \\
\text { sobre a } \\
\text { Educação } \\
\text { Infantil } \\
\end{array}$ & $\begin{array}{c}\text { Evolução da } \\
\text { Restrição de } \\
\text { Crédito sobre } \\
\text { a Educação } \\
\text { Infantil } \\
\end{array}$ & \begin{tabular}{|c} 
Restrição de \\
Crédito sobre a \\
Probabilidade \\
de ser \\
Empresário \\
\end{tabular} \\
\hline \multicolumn{4}{|l|}{ Crédito Formal } \\
\hline Total de Operações de Crédito & 0.0585 & $-0.2272 * *$ & 0.0561 \\
\hline Evolução das Operações de Crédito 1991/2000 & $0.2202 * *$ & $0.209 *$ & 0.0507 \\
\hline $\begin{array}{l}\text { Investimento/Custeio Agricultura por Área } \\
\text { Plantada }\end{array}$ & 0.0962 & 0.106 & $-0.1455^{*}$ \\
\hline Investimento/Custeio Agricultura 1991/2000 & 0.1118 & 0.0529 & 0.0841 \\
\hline $\begin{array}{l}\text { Investimento/Custeio Pecuária por Efetivo de } \\
\text { Rebanho }\end{array}$ & $-0.1962 * *$ & -0.1033 & -0.1128 \\
\hline Investimento/Custeio Pecuária 1991/2000 & 0.043 & -0.0338 & -0.0454 \\
\hline Comercialização Agricultura por Área Plantada & -0.0098 & -0.0392 & $-0.2143 * *$ \\
\hline Comercialização Agricultura 1991/2000 & 0.0785 & 0.2296 & 0.1146 \\
\hline Comercialização Pecuária por Efetivo de Rebanho & -0.0806 & 0.3253 & -0.2415 \\
\hline Comercialização Pecuária 1991/2000 & -0.2937 & -0.2581 & 0.069 \\
\hline Agroindústria & 0.0469 & -0.1735 & -0.0213 \\
\hline Agroindústria 1991/2000 & 0.2853 & -0.1084 & -0.0397 \\
\hline \multicolumn{4}{|l|}{ PRONAF } \\
\hline Custeio 2000 & 0.0798 & $-0.2154^{* *}$ & 0.1081 \\
\hline Custeio 2004 & 0.0616 & $-0.1984^{*}$ & 0.0892 \\
\hline Variação do PRONAF Custeio entre 2000 e 2004 & 0.0411 & -0.0704 & -0.0889 \\
\hline Investimento 2000 & 0.1469 & 0.0673 & 0.0098 \\
\hline Investimento 2004 & 0.089 & -0.1314 & 0.0917 \\
\hline $\begin{array}{l}\text { Variação do PRONAF Investimento entre } \\
2000 \text { e } 2004\end{array}$ & 0.1149 & -0.0325 & -0.0222 \\
\hline Total de Contratos PRONAF Custeio em 2000 & 0.0624 & $-0.1851 *$ & 0.1054 \\
\hline Total de Contratos PRONAF Custeio em 2004 & 0.067 & -0.1619 & 0.0943 \\
\hline Total de Contratos PRONAF Investimento em 2000 & 0.1143 & 0.0521 & 0.0388 \\
\hline Total de Contratos PRONAF Investimento em 2004 & 0.063 & 0.0852 & -0.0239 \\
\hline
\end{tabular}

*significativo a $10 \%,{ }^{* *}$ significativo a $5 \%,{ }^{* * *}$ significativo a $1 \%$

Fonte: Elaboração Própria a partir de dados dos Censos Demográficos 1991/2000 (IBGE), COSIF/ BACEN e PRONAF/Ministério do Desenvolvimento Agrário. 
Quanto à relação entre a restrição de crédito sobre a probabilidade de ser empresário e o crédito formal, há uma correlação negativa entre o financiamento concedido para a agricultura por área plantada, em 2000, e a restrição de crédito. As microrregiões mais restritas ao crédito, em 2000, foram as que receberam menos crédito para a agricultura. Logo, embora o crédito para agricultura apresente uma tendência à desconcentração regional, a mesma parece não ter favorecido aos chefes entre 20 e 29 anos.

Por fim, analisando as correlações dos coeficientes da restrição de crédito e os empréstimos do PRONAF, aparecem correlações negativas e significativas a $5 \%$ e $10 \%$ entre a restrição de crédito sobre a educação infantil e o total de empréstimos para custeio em 2000 e 2004, como também com o total de contratos para custeio em 2004. Os dados apontam para a possibilidade de que os financiamentos do PRONAF para custeio tenham sido maiores em regiões onde houve um maior aperto do crédito entre 1991 e 2000, o que é um resultado semelhante ao encontrado para a evolução do total das operações de crédito; a diferença aqui é que os dados analisados do PRONAF referem-se apenas ao período iniciado no ano 2000.

\section{Conclusão}

O artigo tem, como objetivo, a documentação das condições de crédito das famílias brasileiras que vivem no meio rural. Foi considerada tanto a situação de 2000, como a evolução ao longo da década de 1990.

Por diferentes razões, o acesso das famílias brasileiras ao mercado de crédito constitui um tema pouco estudado. Dentre essas razões, destacam-se os problemas com a disponibilidade de dados. Buscando contornar essa questão, a primeira parte do artigo avaliou a importância da restrição de crédito a partir da análise da correlação entre a riqueza e decisões importantes para as famílias que vivem em meio rural. Constatamos que (i) a restrição de crédito é ativa no país como um todo, assim como nas cinco macrorregiões; (ii) há substantiva variação entre as microrregiões; (iii) ao longo da década de 1990 houve um aperto na restrição de crédito de várias microrregiões do Nordeste.

A partir da constatação desses fatos, passamos à análise da situação 
em 2000 do crédito bancário e sua evolução ao longo da década de 1990. O resultado mais surpreendente é que não há uma relação clara entre a restrição de crédito caracterizada na primeira parte do artigo e o montante de crédito bancário, seja em termos do montante total, de qualquer modalidade ligada à agropecuária ou, especificamente, do PRONAF.

Conseqüentemente, temos duas implicações básicas para o desenho de políticas públicas. De um lado, os resultados mostram que há bastante espaço para melhorias no acesso a crédito das famílias pobres que vivem em áreas rurais. Por outro lado, não é claro que as políticas de crédito voltadas para a agricultura sejam capazes de resolver esse problema.

\section{Referências bibliográficas}

BANERJEE, Abhijit V. e NEWMAN, Andrew F (1993). "Occupational Choice and the Process of Development". The Journal of Political Economy. Volume 101, No. 2, p.274-298.

BEHRMAN, Jere R.; FOSTER, D. Andrew; ROSENZWEIG, Mark R.; e VASHISHTHA, Prem (1997). “Women's Schooling, Home Teaching, and Economic Growth". University of Pennsylvania, mimeo.

BRANDÃO, Antônio Salazar P. e MAGALHÃES, Uriel de (1982). Crédito rural: problemas econômicos e sugestões de mudança. Ensaios econômicos da EPGE. $\mathrm{n}^{\circ}$. 35. Rio de Janeiro.

DIAS, F. M.; MAGALHÃES, A. M.; SILVEIRA NETO, R.; BARROS, A. R (2004). A experiência recente do PRONAF em Pernambuco: uma análise através de propensity score Anais do XXXII Encontro Nacional de Economia. João Pessoa, Paraíba.

EVANS, David S. e JOVANOVIC, Boyan (1989). "An Estimated Model of Entrepreneurial Choice under Liquidity Constraints". Journal of Political Economy, Volume 97, No. 4, p. 808-827.

GALOR, Oded; ZEIRA, Joseph (1993). "Income Distribution and Macroeconomics," Review of Economic Studies 66.

GASQUES, J. G.; VILLA VERDE, C. M. e OLIVEIRA, J. A. de (2004). Crédito rural e estruturas de financiamento. Texto para discussão $\mathbf{n}^{\mathbf{0}}$. 1036. IPEA, Brasília. 
GHATAK, Maitreesh e JIANG, Neville Nien-Huein (2002). "A Simple Model of Inequality, Occupational Choice, and Development". Journal of Development Economics. Volume 69, p.205-226.

GHOSH, P.; MOOKHERJEE e RAY, D. (2000) "Credit rationing in developing countries: an overview of the theory", chapter 11 in Readings in the Theory of Economic Development, edited by D. Mookherjee and D. Ray, London: Blackwell, pp. 383-401.

MATTEI, Lauro (2001). Programa Nacional de Fortalecimento da Agricultura Familiar (PRONAF): concepção, abrangência e limites observados. IV Encontro da Sociedade Brasileira de Sistemas de Produção. Belém, Pará.

NEDER, D. H.; SOUZA FILHO, H.; SILVEIRA, J.M.; MAGALHÃES, M. e BUAINAIN, A. M (2005). Análise dos fatores condicionantes dos resultados da reforma agrária no Brasil. Anais do XXXIII Encontro Nacional de Economia. Natal, Rio Grande do Norte.

PAULSON, Anna L. e TOWNSEND, Robert (2001). "Entrepreneurship and Financial Constraints in Thailand". mimeo.

REZENDE, G. e BUAINAIN, A. (1994). Structural adjustment and agriculture in Brazil: the experience of the 1980's. Revista Brasileira de Economia. Vol. 48 (4). Rio de Janeiro.

REZENDE, Gervásio de Castro (1985). A agricultura e a reforma do crédito rural. Revista Brasileira de Economia. Vol. 39 (2). Rio de Janeiro.

Recebido em março de 2006 e revisto em dezembro de 2006 